\title{
A Database of the Structural and Electronic Properties of Prussian Blue, Prussian White, and Berlin Green Compounds through Density Functional Theory
}

\author{
Franziska Simone Hegner, ${ }^{\dagger}$ José Ramón Galán-Mascarós, ${ }^{\dagger, \ddagger}$ and Núria López ${ }^{*}{ }^{\dagger}$ \\ ${ }^{\dagger}$ Institute of Chemical Research of Catalonia ICIQ The Barcelona Institute of Science and Technology, Av. Països Catalans 16, \\ 43007 Tarragona, Spain \\ ${ }^{\ddagger}$ Catalan Institution for Research and Advanced Studies ICREA, Passeig Lluís Companys, 08010 Barcelona, Spain
}

\section{Supporting Information}

\begin{abstract}
Prussian blue and its related compounds are formed by cheap and abundant metals and have shown their importance in the generation of new fuels by renewable sources. To optimize these compounds it is important to understand their electronic structure and thus establish robust structure-activity relationships. To this end, we employed theoretical simulations based on density functional theory, employing functionals of different degree of complexity, including pure generalized gradient approximation (GGA) and GGA+U functionals, which introduce self-interaction correction terms through the Hubbard parameter, and compared those to the hybrid functionals HSE03 and HSE06. With this robust setup, we can identify an appropriate computational scheme that provides the best compromise between computational demand and accuracy. A complete database considering Berlin green and Prussian blue and white for all alkaline cations is presented.
\end{abstract}

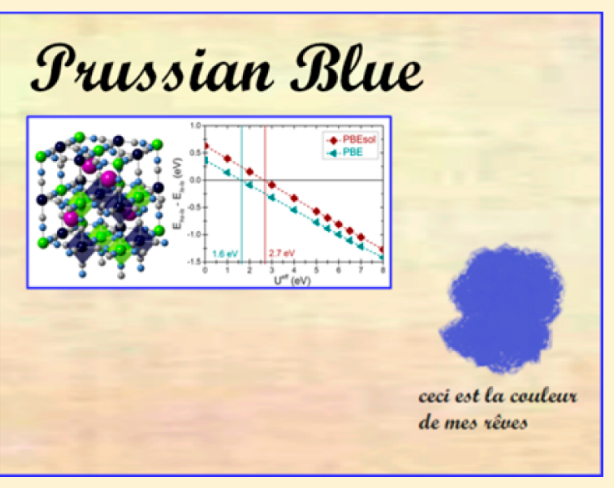

\section{INTRODUCTION}

Prussian blue-type compounds are a fascinating class of materials with high potential in the new energies field. These metalhexacyanometallates have the generic formula $\mathrm{A}_{x} \mathrm{M}_{y}^{\mathrm{a}}\left[\mathrm{M}^{\mathrm{b}}(\mathrm{CN})_{6}\right]_{z}$ with $\mathrm{M}^{\mathrm{a}, \mathrm{b}}$ being cheap and abundant transition metals and $\mathrm{A}$ the countercation, typically an alkaline metal. In the lattice, the two transition-metal centers have different coordination spheres, and, as a consequence they can adapt several oxidation states and magnetic configurations. This opens up a vast variety of applications, such as electrochromism, ${ }^{1}$ energy storage, ${ }^{2,3}$ watersplitting catalysis, ${ }^{4,5}$ analytical sensors, ${ }^{6}$ radio waste detection, ${ }^{7}$ multienzyme mimetics, ${ }^{8}$ magnetic switches, ${ }^{9,10}$ and roomtemperature magnets. ${ }^{11}$ The drawback of this physical and chemical versatility is that its electronic structure modeling is challenging and, thus, limiting the understanding of these materials and the establishment of structure-activity relationships. Without a proper description of their electronic structure it is impossible to rationally design the new generation of Prussian-blue $(\mathrm{PB})$ derivatives with tailored properties.

The parent compound is $\mathrm{PB}\left(\mathrm{Fe}_{4}\left[\mathrm{Fe}(\mathrm{CN})_{6}\right]_{3} \cdot x \mathrm{H}_{2} \mathrm{O}(x=\right.$ 14-16)), sometimes also called Prussian blue. The real crystal structure, which was determined by $\mathrm{X}$-ray ${ }^{12,13}$ and neutron ${ }^{14}$ diffraction studies, is shown in Figure 1a. It consists of two octahedrally coordinated iron centers, namely, ferric Fe(III) and ferrous $\mathrm{Fe}(\mathrm{II})$, being linked by cyanide bridges with lattice constants varying from 10.13 to $10.18 \AA \AA^{12-14}$ Assuming classical oxidation states, the $\mathrm{N}$-coordinated $\mathrm{Fe}$ has a charge of +3 , whereas the $\mathrm{C}$-coordinated iron has a charge of $+2 .^{15-18}$
In the following discussion they will therefore be denoted as $\mathrm{Fe}(\mathrm{III})-\mathrm{N}$ and $\mathrm{Fe}(\mathrm{II})-\mathrm{C}$, respectively. The fact of comprising two weakly interacting metal centers of the same kind ( $\mathrm{Fe}$ in this case) with different electronic structures classifies $\mathrm{PB}$ as a class(II) mixed-valence compound. ${ }^{19}$

Because of the strong ligand field of the cyanide $\mathrm{C}, \mathrm{Fe}$ (II)-C always adopts a diamagnetic low-spin (ls) $\mathrm{d}^{6}$ configuration with $S=0 . \mathrm{Fe}(\mathrm{III})-\mathrm{N}$ is found in a paramagnetic high-spin (hs) $\mathrm{d}^{5}$ state $(S=5 / 2)$ in the weaker field of the N-ligand ${ }^{14,18,20,21}$ (see Figure 1). The $\mathrm{Fe}(\mathrm{III})-\mathrm{N}$ moments order and align ferromagnetically below $T_{c}=5.6 \mathrm{~K}^{14,18,22}$ The observed ferromagnetic interaction can arise through electron delocalization via the ligand $\pi$-orbital ${ }^{23}$ or via a direct through-space coupling of the diagonal paramagnetic $\mathrm{Fe}(\mathrm{III})-\mathrm{N}$ centers. ${ }^{24}$ Upon electromagnetic irradiation or changes in pressure or temperature, the iron centers might undergo transitions between their hs and ls states. This is why PB is also regarded as a spincrossover (SCO) compound. The strong charge-transfer (CT) absorption between $1 s d^{6} t_{2 g} \mathrm{Fe}(\mathrm{II})-\mathrm{C}$ and hs $d^{5} t_{2 g} \mathrm{Fe}(\mathrm{III})-\mathrm{N}$ at $\sim 1.75 \mathrm{eV}^{25}$ causes the intense blue color of the compound, from which $\mathrm{PB}$ got its name.

In this computational study we assume an ideal stoichiometric model structure $\mathrm{KFe}\left[\mathrm{Fe}(\mathrm{CN})_{6}\right]$, which is shown in Figure $1 \mathrm{~b}$, as its main properties are expected to be similar to the real structure. As seen in Figure 1, the N-coordinated Fe(III) centers occupy the

Received: September 14, 2016

Published: December 6, 2016 

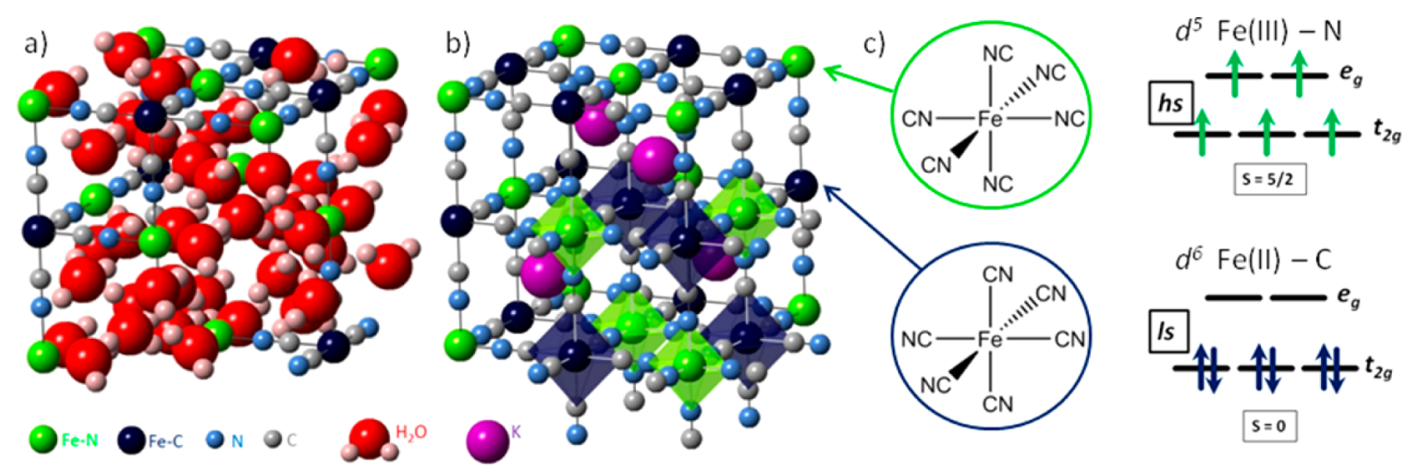

Figure 1. PB: (a) as-prepared nonstoichiometric $\mathrm{PB}\left(\mathrm{Fe}_{4}\left[\mathrm{Fe}(\mathrm{CN})_{6}\right]_{3} \cdot x \mathrm{H}_{2} \mathrm{O}(x=14-16)\right)$, (b) crystalline model structure $\left(\mathrm{KFe}\left[\mathrm{Fe}(\mathrm{CN})_{6}\right]\right)$, and (c) octahedral coordinated Fe-centers and their spin configurations. Here we used the conventional orbital notations " $\mathrm{e}_{\mathrm{g}}$ " and " $\mathrm{t}_{2 \mathrm{~g}}$ " for molecular octahedral point groups (local coordination), which must be regarded with caution, as a different symmetry may be superimposed by the crystalline lattice.
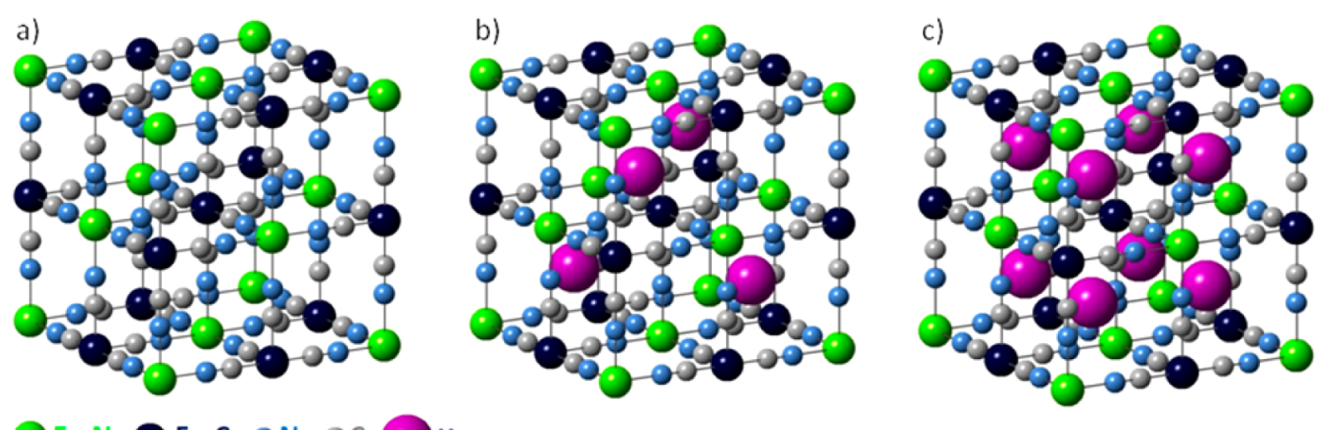

$\odot$ Fe-N $\odot$ Fe-C ON OC $\bigcirc \mathrm{K}$

Figure 2. a Berlin Green, $B G\left(\mathrm{Fe}\left[\mathrm{Fe}(\mathrm{CN})_{6}\right]\right)$, a Prussian Blue, $\mathrm{PB}\left(\mathrm{KFe}\left[\mathrm{Fe}(\mathrm{CN})_{6}\right]\right)$, and a Prussian White, $\mathrm{PW}\left(\mathrm{K}_{2} \mathrm{Fe}\left[\mathrm{Fe}(\mathrm{CN})_{6}\right]\right)$.

corners of a face-centered cubic $(f c c)$ lattice of the crystal group $F \overline{4} 3 m$, whereas $\mathrm{Fe}(\mathrm{II})-\mathrm{C}$ is placed at the middle of the edges. ${ }^{13,14}$ Alkali-metal cations, in this case potassium $\mathrm{K}^{+}$, occupy half of the tetrahedral holes of the lattice for compensating the charge of the negatively charged cyanide complexes. In the older literature, $\mathrm{KFe}\left[\mathrm{Fe}(\mathrm{CN})_{6}\right]$ is often referred to as "soluble" $\mathrm{PB}$, whereas $\mathrm{Fe}_{4}\left[\mathrm{Fe}(\mathrm{CN})_{6}\right]_{3} \cdot x \mathrm{H}_{2} \mathrm{O}$ is named "insoluble" $\mathrm{PB} .{ }^{18,26}$ To our knowledge, pure $\mathrm{KFe}\left[\mathrm{Fe}(\mathrm{CN})_{6}\right]$ has never been synthesized. The ideal mixed-valence iron(III)iron(II) PB has been subject of computational studies for the last two decades. ${ }^{21,24,27-32}$ Wojdel et al. did pioneering work applying density functional theory (DFT) to PB-type compounds ${ }^{21,27-30,33}$ and successfully reproduced experimental data while applying mixed ultrasoft pseudopotentials (USPPs) ${ }^{28}$ and, in more recent studies, GGA+U with different Hubbard $U$ correction terms on both iron centers. ${ }^{27}$ To investigate magnetic interactions in PB, Middlemiss and Wilson applied hybrid functionals with different amounts of Hartree-Fock type of exchange and reported a more accurate representation of intervalence charge transfer. ${ }^{24}$

$\mathrm{PB}$ related compounds include oxidized Berlin green (BG; $\left.\mathrm{Fe}(\mathrm{III})\left[\mathrm{Fe}(\mathrm{III})(\mathrm{CN})_{6}\right]\right)$ and reduced Prussian white (PW; $\mathrm{K}_{2} \mathrm{Fe}(\mathrm{II})\left[\mathrm{Fe}(\mathrm{II})(\mathrm{CN})_{6}\right]$ ) and are shown in Figure 2. BG, which is sometimes also called Prussian yellow, has both iron centers in a +3 oxidation state. ${ }^{34,35}$ The negative charge of the cyanide ligands is balanced by the highly oxidized iron centers and, therefore, no counter cations need to be introduced in the lattice (Figure 2a). PW, or Everitt's salt, is the fully reduced counterpart with both iron centers in a +2 oxidation state and with all of its tetrahedral holes occupied by alkali cations (Figure 2b). ${ }^{36}$ As it is the case for the parent $\mathrm{PB} \mathrm{KFe}(\mathrm{III})\left[\mathrm{Fe}(\mathrm{II}) \mathrm{CN}_{6}\right]$, the
C-coordinated Fe center is expected to remain in a ls configuration independent of its oxidation state, which is due to the strong $\mathrm{CN}$ ligand field. In the intermediate field of the $\mathrm{N}$-coordinating cyanide, $\mathrm{Fe}-\mathrm{N}$ may change its spin configuration. ${ }^{30,37}$ In contrast to insulating $\mathrm{PB}$, both redox forms show electronic conduction. ${ }^{30,35,38}$

In the present work, we revise the case of $\mathrm{PB}$ by applying different density functional methods and testing their influence on important structural and electronic parameters. Furthermore, we applied the determined most appropriate methods to describe the fully oxidized form BG and the reduced form PW. The effect of cation insertion, when going from $B G$ to $P B$ and from $\mathrm{PB}$ to $\mathrm{PW}$, as well as the influence of different counter cations, on the electronic and geometric structures were investigated and discussed.

\section{COMPUTATIONAL METHODS}

DFT calculations were performed using the Vienna Ab Initio Package. ${ }^{39,40}$ To benchmark the performance of pure DFT functionals, we employed the generalized gradient approximations (GGAs) Perdew-Burke-Ernzerhof (PBE), ${ }^{41,42}$ Perdew-Burke-Ernzerhof revised for solids (PBEsol), ${ }^{43}$ revised Perdew-Burke-Ernzerhof (revPBE or RP) ${ }^{44}$ Perdew-Wang 91 (PW91), ${ }^{45,46}$ and Armiento and Mattsson 2005 (AM05). ${ }^{47}$ Pure DFT has been shown to be insufficient in describing the correct magnetic and electronic structure of the mixed valence compound (see Supporting Information Table S1). One solution to this problem is to introduce additional on-site interaction energies on the d-metal centers, the Coulomb interaction $U$, and the electronic exchange $J{ }^{48}$ Dudarev's approach of GGA+U, ${ }^{48,49}$ adding an effective $U$ parameter $U^{\text {eff }}=|U-J|$ to the GGA functionals PBE and PBEsol, and examining the dependence of main parameters on the $U^{\text {eff }}$ value, was applied in our case. In addition, hybrid functionals, which 
a)

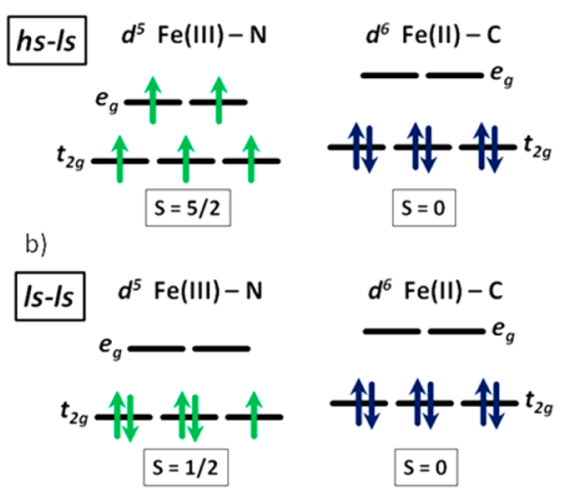

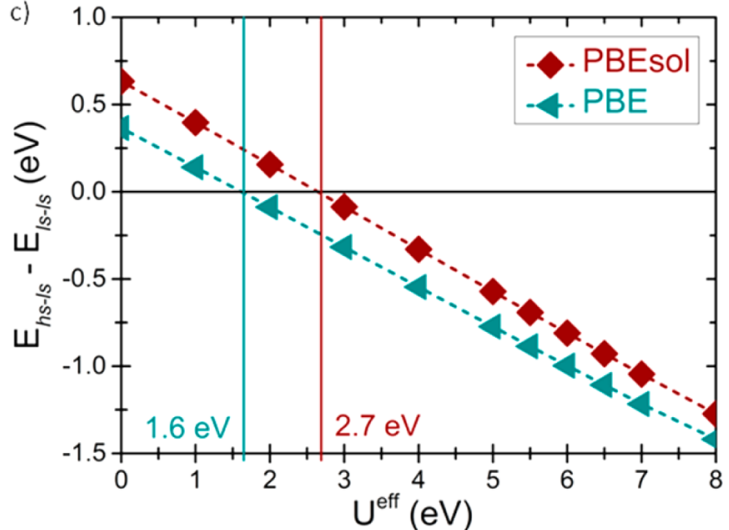

Figure 3. Energy dependence of the (a) hs-ls (hs $\mathrm{Fe}(\mathrm{III})-\mathrm{N}-\mathrm{ls} \mathrm{Fe}(\mathrm{II})-\mathrm{C}$ ) and (b) ls-ls (ls $\mathrm{Fe}(\mathrm{III})-\mathrm{N}-\mathrm{ls} \mathrm{Fe}(\mathrm{II})-\mathrm{C})$ configurations on the effective $U$ parameter $U^{\mathrm{eff}}=\mid U-J \mathrm{~J}$. (c) The energy difference $E_{\mathrm{hs}-\mathrm{ls}}-E_{\mathrm{ls}-\mathrm{s}}$ is a measure if and how much the hs-ls ground state is stabilized over the diamagnetic ls-ls state with varying $U^{\text {eff }}$.
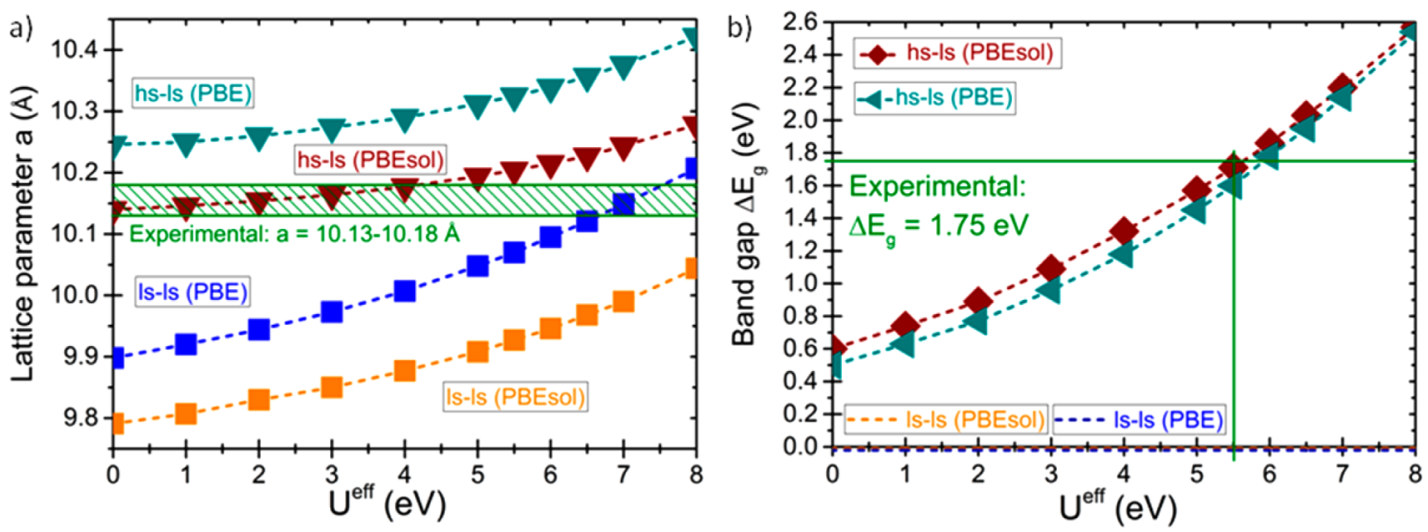

Figure 4. Variation of the effective $U$ parameter $U^{\text {eff }}=|U-J|$ and its influence on (a) the lattice parameter and (b) the band gap.

include a defined amount of exact exchange from Hartree-Fock theory, ${ }^{50}$ were applied. The HSE functionals (HSE03 and HSE06), which were developed especially for solids, compromise computational efficiency and accuracy. ${ }^{51,52}$ Both HSE03 and HSE06 were used as a benchmark. ${ }^{51-53}$ For the hybrid, as well as for PBEsol+U, functionals the geometric and electronic structures of all the systems with $\mathrm{K}_{n} \mathrm{Fe}\left[\mathrm{Fe}(\mathrm{CN})_{6}\right]$ stoichiometry representing the $\mathrm{PB}(n=1)$, BG $(n=0)$, and PW $(n=2)$, were investigated.

All calculations assume model anhydrous structures with a facecentered $\bar{F} \overline{4} 3 m$ unit cell, as shown in Figures $1 \mathrm{~b}$ and 2 and with zero $(\mathrm{BG})$, four $(\mathrm{PB})$, or eight $(\mathrm{PW})$ counter cations placed in the tetrahedral positions of the lattice. Inner electrons were replaced by plane wave projector augmented wave (PAW) method. To ensure accuracy, we applied small PAW pseudopotentials, expanding valence and valence-subshell s- and p-electrons, for all metals in the lattice. ${ }^{54,55}$ Spin-polarized GGA and GGA+U calculations were performed using a high precision and cutoff energy $(700 \mathrm{eV})$. The Brillouin zone was sampled using a Monkhorst-Pack $k$-point mesh $^{56}$ with $5 \times 5 \times$ $5 k$-points for lattice optimizations and $9 \times 9 \times 9 k$-points for static density of states (DOS) calculations, respectively. High precision static calculations were performed with a cutoff energy of $600 \mathrm{eV}$. $\gamma$-Centered hybrid calculations were performed with a cutoff energy of $500 \mathrm{eV}$, while inheriting the charge density from previous PBEsol or $\mathrm{PBEsol}+\mathrm{U}$ calculations.

\section{RESULTS AND DISCUSSION}

3.1. Electronic Structure of the Parent Compound Prussian Blue. 3.1.1. DFT $+U$. The structure of $\mathrm{KFe}[\mathrm{Fe}-$ $\left.(\mathrm{CN})_{6}\right]$ was calculated using different regular DFT functionals, which converged to an overall low-spin (ls-ls) ground state with both Fe centers in an ls configuration, as shown in Figure $3 \mathrm{~b}$ (Supporting Information Table S1). Also meta-GGAs, such as TPSS, stabilize the ls-ls state over the hs-ls state. (Table S1) Experimental data, however, supports a hs-ls configuration (Figures $1 \mathrm{c}$ and $3 \mathrm{c}$ ), where the $\mathrm{N}$-coordinated Fe centers adopt a hs $\mathrm{d}^{5}$ state, since the crystal field of the cyanide $\mathrm{N}$-site is relatively weak. ${ }^{14,18,20,21}$ The convergence to an incorrect magnetic ground state is due to the lack of DFT describing electronic and magnetic interactions on transition-metal centers. ${ }^{50}$ We performed a systematic scan of effective $U^{\text {eff }}$ parameters ranging from 0.0 to $8.0 \mathrm{eV}$, applying both DFT functionals PBE and PBEsol (Supporting Information Tables S2 and S3). The $U^{\text {eff }}$ dependence of the energies of the low-lying hs-ls and ls-ls magnetic configurations is shown in Figure 3c.

It can be seen in Figure 3 that an effective parameter $U^{\text {eff }} \geq$ $1.6 \mathrm{eV}$ for PBE, and $U^{\text {eff }} \geq 2.7 \mathrm{eV}$ for PBEsol, respectively, is necessary to stabilize the hs-ls state over the ls-ls state. This shows clearly the importance of electronic correlation on the magnetic configuration. It is noted that other spin combinations, such as an overall high-spin hs-hs state and mixed configurations, were excluded, as they are very high in energy (Supporting Information Table S4). The same is true for the anti-ferromagnetic alignment of the magnetic moments on separate sites, which is disfavored by spin-delocalization and, possibly, direct coupling as well. ${ }^{23,24}$

Complementary, Figure 4 shows the dependence of the band gap and the lattice parameter with varying $U^{\text {eff }}$ for both DFT functionals PBE and PBEsol. The lattice constant for the hs-ls 
Table 1. Structural and Electronic Parameters of the Ideal KFe(III) [Fe(II) (CN) $]$ in a High-Spin-Low-Spin Magnetic Configuration Calculated for the Different Functionals PBE, PBEsol, PBE+U, PBEsol+U (with $U^{\text {eff }}=5.5$ eV), HSE03, and HSE0 $^{a}{ }^{a}$

\begin{tabular}{|c|c|c|c|c|c|c|c|}
\hline functional & PBE & PBEsol & $\mathrm{PBE}+\mathrm{U}$ & PBEsol+U & HSE03 & HSE06 & expt \\
\hline$a, \AA$ & 10.246 & 10.141 & 10.325 & 10.204 & 10.184 & 10.175 & $10.166^{13}$ \\
\hline$d(\mathrm{Fe}-\mathrm{N}), \AA$ & 2.070 & 2.043 & 2.076 & 2.050 & 2.053 & 2.051 & $2.03^{13}$ \\
\hline$d(\mathrm{Fe}-\mathrm{C}), \AA$ & 1.875 & 1.851 & 1.911 & 1.877 & 1.873 & 1.872 & $1.92^{13}$ \\
\hline$d(\mathrm{C}-\mathrm{N}), \AA$ & 1.177 & 1.177 & 1.176 & 1.175 & 1.165 & 1.165 & $1.13^{13}$ \\
\hline$E_{\mathrm{hs}-\mathrm{ls}}-E_{\mathrm{ls}-\mathrm{l} s}, \mathrm{eV}$ & +0.37 & +0.63 & -0.88 & -5.53 & -0.69 & -0.31 & \\
\hline$\Delta E_{\mathrm{g}}, \mathrm{eV}$ & 0.50 & 0.60 & 1.59 & 1.73 & 1.94 & 2.31 & $1.75^{25}$ \\
\hline $\mathrm{CFSE}_{\mathrm{Fe}(\mathrm{III})-\mathrm{N}}, \mathrm{eV}$ & 1.50 & 1.67 & 1.13 & 1.39 & 1.69 & 1.73 & \\
\hline $\mathrm{q}_{\mathrm{Fe}(\mathrm{III})-\mathrm{N}},\left|\mathrm{e}^{-}\right|$ & 1.61 & +1.74 & +1.73 & +1.87 & +1.86 & +1.87 & \\
\hline $\mathrm{q}_{\mathrm{Fe}(\mathrm{II})-\mathrm{C}}, \mathrm{le}^{-} \mid$ & +0.97 & +0.55 & +1.01 & +1.08 & +0.76 & +0.76 & \\
\hline $\mathrm{q}_{\mathrm{N}},\left|\mathrm{e}^{-}\right|$ & -1.25 & -1.42 & -1.31 & -1.36 & -1.37 & -1.38 & \\
\hline $\mathrm{q}_{\mathrm{C}}, \mathrm{le}^{-} \mathrm{I}$ & +0.67 & +0.88 & +0.70 & +0.72 & +0.78 & +0.79 & \\
\hline $\mathrm{q}_{\mathrm{K}}, \mid \mathrm{e}^{-1}$ & +0.93 & +0.93 & +0.93 & +0.93 & +0.94 & +0.94 & \\
\hline$\mu_{\mathrm{Fe}(\mathrm{III}) \mathrm{N}}, \mu_{\mathrm{B}}$ & 3.86 & 3.84 & 4.24 & 4.22 & 4.15 & 4.16 & $5.98^{14}$ \\
\hline$\mu_{\mathrm{Fe}(\mathrm{II})-\mathrm{C}}, \mu_{\mathrm{B}}$ & 0.35 & 0.31 & 0.16 & 0.17 & 0.27 & 0.26 & \\
\hline$\mu_{\mathrm{N}}, \mu_{\mathrm{B}}$ & $0.06-0.07$ & $0.06-0.07$ & 0.05 & 0.05 & 0.05 & 0.05 & \\
\hline$\mu_{\mathrm{C}}, \mu_{\mathrm{B}}$ & 0.02 & 0.02 & 0.02 & 0.02 & 0.01 & 0.01 & \\
\hline$\mu_{\mathrm{K}}, \mu_{\mathrm{B}}$ & 0.00 & 0.00 & 0.00 & 0.00 & 0.00 & 0.00 & \\
\hline
\end{tabular}

${ }^{a_{T}}$ The energy difference $E_{\mathrm{hs}-\mathrm{ls}}-E_{\mathrm{ls}-\mathrm{ls}}$ is a measure if and how much the hs-ls ground state is stabilized over the diamagnetic ls-ls state. The band gap $\Delta E_{\mathrm{g}}$ results from the charge transfer from $\mathrm{Fe}(\mathrm{II})-\mathrm{C}_{2 \mathrm{~g}}$ to $\mathrm{Fe}(\mathrm{III})-\mathrm{N} \mathrm{t}_{2 \mathrm{~g}}$. The crystal field splitting energy $\left(\mathrm{CFSE}_{\mathrm{Fe}(\mathrm{III})-\mathrm{N}}\right)$ is the energy difference of $\mathrm{Fe}(\mathrm{III})-\mathrm{N} \mathrm{t}_{2 \mathrm{~g}}$ and $\mathrm{e}_{\mathrm{g}}$.

state is much larger than for the ls-ls state, which was expected, since $\mathrm{e}_{\mathrm{g}}$-antibonding orbitals are populated, giving rise to a larger $\mathrm{Fe}(\mathrm{III})-\mathrm{N}$ distance (Figure $4 \mathrm{a}$ ). The ls-ls configuration always remains conducting, independent of applied $U^{\text {eff }}$ (Figure 4b). For hs-ls PB, the bandgaps increase with the chosen value of $U^{\text {eff }}$. As stronger the effective on-site Coulomb interaction, as narrower get the d-bands and as larger gets the bandgap. At values of $U^{\text {eff }}=6.0 \mathrm{eV}(\mathrm{PBE})$ and $U^{\text {eff }}=5.5 \mathrm{eV}$ (PBEsol), the band gaps are closest to the experimental band gap $\Delta E_{\mathrm{g}}=1.75 \mathrm{eV}^{2 \mathrm{~S}}$ (Figure $4 \mathrm{~b}$ and Supporting Information Tables S2 and S3). This finding is in relatively good agreement with the value $U^{\text {eff }}=5.3 \mathrm{eV}$, found by calculating redox energies for $\mathrm{Fe}(\mathrm{II})$ and $\mathrm{Fe}(\mathrm{III}){ }^{57}$ Especially for optoelectronics applications, a correct prediction of the band gap is crucial. Thus, it was the main criterion to choose the optimal $U^{\text {eff }}$ parameter, which will be set to $5.5 \mathrm{eV}$ throughout further discussion.

3.1.2. Functional Comparison. A comparison of the functionals PBEsol, PBEsol+U, HSE03, HSE06 is shown in Table 1. We also investigated other hybrid functionals, such as, for example, B3LYP ${ }^{58}$ and B3LYP*,59 which generally yielded similar results. However, we chose to use HSE-type functionals, as they are optimized especially for periodic solids (see Supporting Information Table S5).

All obtained lattice parameters lie in a range of $\sim 1 \%$ and are in relatively good agreement with the literature values, which vary between 10.13 and $10.17 \AA^{13,14}$ However, the experimental values correspond to the non-stoichiometric lattice $\mathrm{Fe}_{4}\left[\mathrm{Fe}(\mathrm{CN})_{6}\right]_{3} \cdot x \mathrm{H}_{2} \mathrm{O}$. The lattice constants increase slightly with increasing $U^{\text {eff, }}$, which can also be seen in Figure 4a. Because of the higher charge localization on the transitionmetal centers, less charge density can be found in the interstitial bonding regions, leading to an increase in the metal-ligand distances and, hence, the overall lattice parameter. Compared to the hybrid functionals and literature values, PBEsol $(+\mathrm{U})$ seems to perform slightly better than PBE $(+\mathrm{U})$.

As for the Bader charges, ${ }^{60-62}$ presented in Table 1 the Fe charges lie well below their classical, ionic limits of $+3\left|\mathrm{e}^{-}\right|$
$\left(q_{\mathrm{Fe}(\mathrm{III})-\mathrm{N}}\right)$ and $+2 \mathrm{le}^{-} \mid\left(q_{\mathrm{Fe}(\mathrm{II})-\mathrm{C}}\right)$, due to metal-ligand bonding. This effect of charge delocalization is also reflected in a significant amount of positive charge $\left(+0.7-0.9 \mathrm{le}^{-} \mathrm{l}\right)$ on the carbon ions, while the ligand's negative charge density is borne by the nitrogen atom. Applying the $U^{\text {eff }}$ parameter leads to a small increase of localized charges on both Fe centers and, hence, an increase in ionic character. Similar arguments apply for the magnetic moments, which are delocalized through orbital overlap with the ligand, mainly the $\mathrm{N}$ atom, by the socalled spin-delocalization mechanism. ${ }^{23}$ With PBE and PBEsol alone the magnetic moment on $\mathrm{Fe}(\mathrm{III})-\mathrm{N}$ is significantly smaller $\left(\mu \approx 3.8-3.9 \mu_{\mathrm{B}}\right)$ than its theoretical value of $5.92 \mu_{\mathrm{B}}$ for the isolated hs $\mathrm{Fe}$ (III) atom, while it is slightly larger on $\mathrm{Fe}(\mathrm{II})-\mathrm{C}\left(\mu \approx 0.3 \mu_{\mathrm{B}}\right)$ than for isolated ls $\mathrm{Fe}(\mathrm{II})\left(\mu_{\mathrm{B}}=0\right)$. As $U^{\text {eff }}$ increases electron correlation and, therefore, localizes electrons on the Fe centers, the magnetic moment on $\mathrm{Fe}(\mathrm{III})-\mathrm{N}$ increases, while it decreases on $\mathrm{Fe}(\mathrm{II})-\mathrm{C}$ with $U^{\text {eff }}$. This effect is slightly less pronounced in HSE03 and HSE06, which may indicate a slight overlocalization of charges with PBEsol+U.

The band gap is given as the energy difference between valence $\mathrm{Fe}(\mathrm{II})-\mathrm{C} \quad t_{2 g}$ and conduction $\mathrm{Fe}(\mathrm{III})-\mathrm{N} \quad t_{2 g}$ band (with equal spin). A calculation of the band structure (with PBEsol $+\mathrm{U}$ ) shows that the gap corresponds to an indirect $\mathrm{L} \leftarrow \Gamma$ transition of $1.73 \mathrm{eV}$, as it is shown in Figure 5. This is in good agreement with previous theoretical studies of Wojdel et al. ${ }^{28}$ The direct band gaps located at $\Gamma, \mathrm{K}, \mathrm{L}$, and $\mathrm{X}$ are 1.85 , $1.87,1.91,1.92 \mathrm{eV}$, respectively, and, hence, lie very close in energy. This is why many experimental studies declare the highly absorbing $\mathrm{PB}$ as direct band gap semiconductor.

Pure GGA (PBE and PBEsol) lacks in describing the electronic structure around the Fermi level, which leads to a large underestimation of the band gap $\left(\Delta E_{\mathrm{g}}=0.50\right.$ and $\left.0.60 \mathrm{eV}\right)$. By applying an effective potential $U^{\text {eff }}$ on the metal centers, the band gap increases, as it was already seen in Figure $4 \mathrm{~b}$. The more electron correlation energy is added to the transitionmetal centers, the more the valence and conduction bands shift apart. Both hybrids HSE03 and HSE03 overestimate the band 


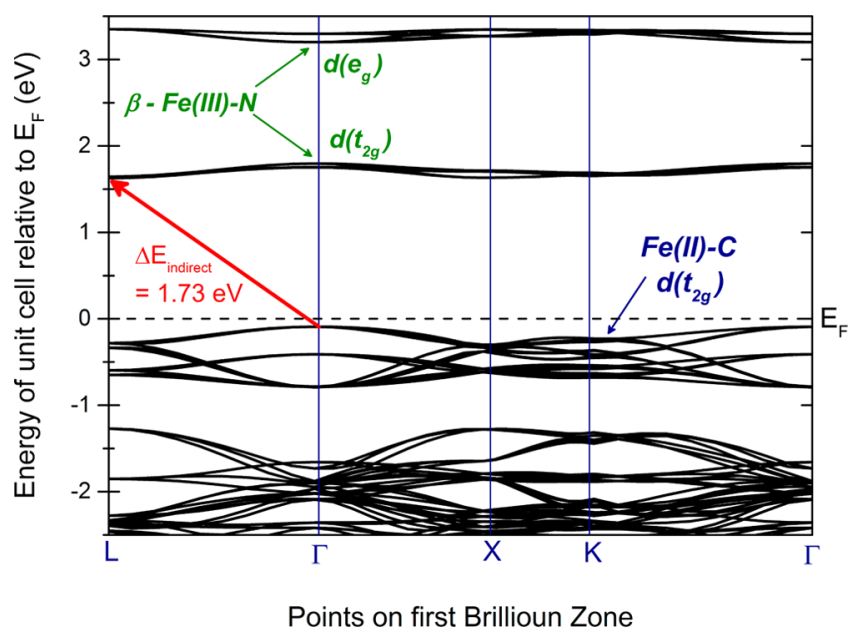

Figure 5. Band structure of hs-ls $\mathrm{PB}$ calculated with PBEsol $+\mathrm{U}$ $(U=5.5 \mathrm{eV})$.

gap, since they are overcorrecting the self-interaction error being inherent to DFT. The value $1.94 \mathrm{eV}$, obtained with HSE03, is in closer agreement to the literature value of $1.75 \mathrm{eV}^{25}$ The difference between the two, otherwise similar, hybrids is due to the screening parameter $\mu$, which defines the distance $2 / \mu$ at which the short-range exact exchange becomes negligible and which strongly influences the band gap. As it was predicted by Krukau et al., ${ }^{53}$ HSE03 with $\mu=0.3 \AA^{-1}$, yields a band gap closer to experiment. The crystal field splitting energy (CFSE) measures the shifts of bands one metal center. Both GGAs (PBE, PBEsol) and hybrids (HSE03, HSE06) give relatively similar crystal field splittings (1.5$1.7 \mathrm{eV}$ ) on the $\mathrm{Fe}(\mathrm{III})-\mathrm{N}$ center. With the additional $U$ correction, however, the $\mathrm{CFSE}_{\mathrm{Fe}(\mathrm{III})-\mathrm{N}}$ decreases significantly, as $U^{\text {eff }}$ squeezes bands on metal center together, thus leading to unphysical terms.

The electronic structures obtained for each functional are visualized as projected DOS in Figure 6. The $\mathrm{K}$ atoms do not participate in the DOS, as they are completely ionized, and they are not shown. PBE $(+\mathrm{U})$ and HSE06 yield DOS very similar to PBEsol $(+\mathrm{U})$ and HSE03, respectively, and are omitted for simplicity.

As it was seen in the variance of charges and magnetic moments, Figure 6 demonstrates that, going from pure GGA (PBEsol) to $\mathrm{GGA}+\mathrm{U}(\mathrm{PBEsol}+\mathrm{U})$ to hybrid (HSE03) functionals, the degree of ionic character increases. DFT alone delocalizes the charge density in the system, resulting in broad, overlapping bands that indicate a large degree of covalency. When going from PBEsol to PBEsol+U this covalency is largely decreased and, even more, in the hybrid calculations, leading to sharper bands. It must be remarked that the notation $e_{g}$ and $t_{2 g}$ is used as a matter of convenience, as it conventionally describes octahedrally coordinated transition-metal complexes. However, the $d_{x y}, d_{x z}$ and $d_{y z}$ orbitals, which define the $t_{2 g}$ set, are no longer degenerate due to the descent in symmetry caused by the insertion of counter cations in the lattice. The same applies for the $e_{g}$ set consisting of $\mathrm{d}_{z}{ }^{2}$ and $\mathrm{d}_{x^{2}-y^{2}}$. This becomes most obvious in the highly accurate DOS plots of HSE03, where we can see a large splitting of the $t_{2 g}$ sets of $\mathrm{Fe}(\mathrm{II})-\mathrm{C}$, as well as of the Fe(III)-N $\beta$ e set. This symmetry distortion can only be seen in the electronic structure, while the overall symmetry of the crystalline lattice remains tetrahedral. The charge-transfer state is indicated by the $1 s t_{2 g}$ set of the $\mathrm{Fe}(\mathrm{III})-\mathrm{N}$ iron center,
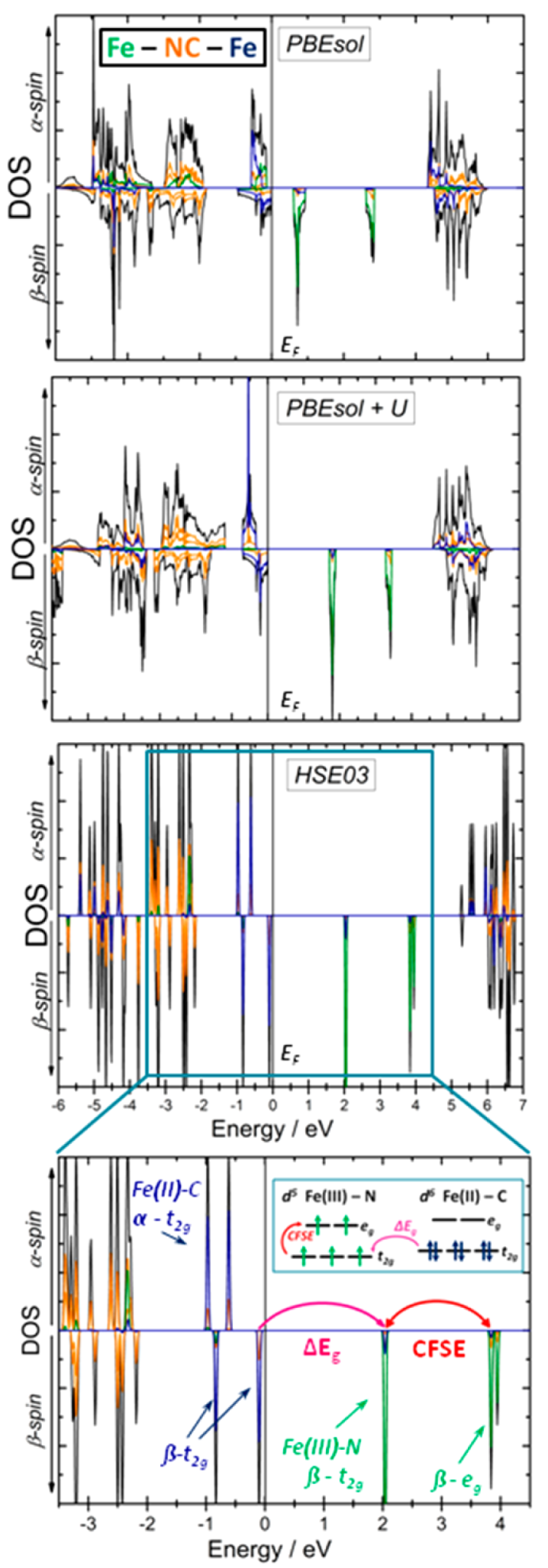

Figure 6. Projected DOS for all atoms in the hs-ls PB lattice for the different functionals PBEsol, PBEsol+U, and HSE03.

which shows some density of the symmetry equivalent $t_{2 g}$ set of $\mathrm{Fe}(\mathrm{II})-\mathrm{C}$, and vice versa. Moreover, the $\mathrm{e}_{\mathrm{g}}$ sets on both metal centers share some electron density, being due to a delocalization of charges via the cyanide bridge, in particular, by the nitrogen p-orbital. ${ }^{22}$ A significant participation of nitrogen in the charge-transfer state can be seen in the DOS as well. 

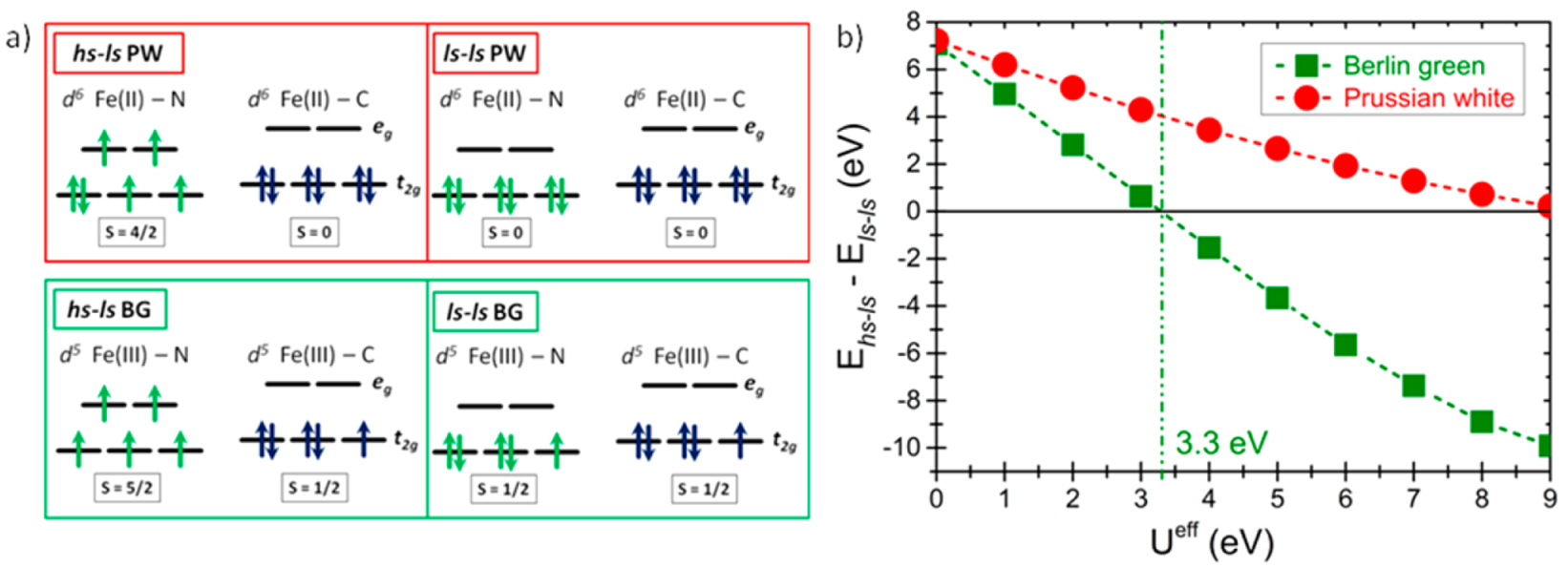

Figure 7. (a) Configurations (hs-ls and ls-ls) of BG and PW and (b) their energy dependence on the effective $U$ parameter $U^{\text {eff }}$.

Table 2. Structural and Electronic Parameters of Berlin Green $\mathrm{Fe}(\mathrm{III})\left[\mathrm{Fe}(\mathrm{III})(\mathrm{CN})_{6}\right]$ and Prussian White $\mathrm{K}_{2} \mathrm{Fe}(\mathrm{II})[\mathrm{Fe}(\mathrm{II})$ $\left.(\mathrm{CN})_{6}\right]$, Obtained with PBEsol+U $\left(U^{\text {eff }}=5.5 \mathrm{eV}\right)$ and $\mathrm{HSE03}^{a}$

\begin{tabular}{|c|c|c|c|c|c|c|c|c|}
\hline \multirow{2}{*}{$\begin{array}{l}\text { functional } \\
\text { compound }\end{array}$} & \multicolumn{3}{|c|}{ PBEsol + U } & \multicolumn{3}{|c|}{ HSE03 } & \multicolumn{2}{|c|}{ experimental } \\
\hline & BG & hs-ls PW & ls-ls PW & BG & hs-ls PW & ls-ls PW & $\mathrm{BG}^{34}$ & $\mathrm{PW}^{36}$ \\
\hline$a, \AA$ & 10.217 & 10.289 & 9.978 & 10.237 & 10.363 & 9.982 & 10.218 & $10.104-10.114^{36}$ \\
\hline$d(\mathrm{Fe}-\mathrm{N}), \AA$ & 2.049 & 2.086 & 1.926 & 2.055 & 2.083 & 1.936 & 2.003 & \\
\hline$d(\mathrm{Fe}-\mathrm{C}), \AA$ & 1.890 & 1.880 & 1.887 & 1.906 & 1.865 & 1.890 & 1.921 & \\
\hline$d(\mathrm{C}-\mathrm{N}), \AA$ & 1.170 & 1.179 & 1.175 & 1.158 & 1.179 & 1.165 & 1.162 & \\
\hline$E_{\mathrm{hs}-\mathrm{ls}}-E_{\mathrm{ls}-\mathrm{ls}}, \mathrm{eV}$ & -0.59 & \multicolumn{2}{|c|}{+0.26} & -0.91 & \multicolumn{2}{|c|}{-0.10} & & \\
\hline$\Delta E_{\mathrm{g}}, \mathrm{eV}$ & cond. & cond. & 3.67 & 1.59 & 2.62 & 4.78 & $\operatorname{cond}^{35,38}$ & $\operatorname{cond}^{38}$ \\
\hline $\mathrm{CFSE}_{\mathrm{Fe}(\mathrm{III})-\mathrm{N}}, \mathrm{eV}$ & 1.32 & & & 0.95 & & & & \\
\hline$q_{\mathrm{Fe}-\mathrm{N}}, \mathrm{le}^{-1}$ & +1.87 & +1.47 & +1.25 & +1.79 & +1.49 & +1.28 & & \\
\hline$q_{\mathrm{Fe}-\mathrm{C}}, \mathrm{le}^{-1}$ & +0.77 & +0.88 & +0.77 & $+1.19-1.20$ & +0.82 & +0.78 & & \\
\hline$q_{\mathrm{N}}, \mathrm{e}^{-} \mid$ & -1.22 & -1.32 & -1.38 & $-1.31-1.34$ & -1.51 & -1.43 & & \\
\hline$q_{\mathrm{C}}, \mathrm{le}^{-} \mathrm{I}$ & +0.78 & +0.62 & +0.74 & $+0.82-0.83$ & +0.82 & +0.78 & & \\
\hline$q_{\mathrm{K}}, \mathrm{e}^{-} \mathrm{I}$ & & +0.93 & +0.92 & & +0.94 & +0.92 & & \\
\hline$\mu_{\mathrm{Fe}(\mathrm{III})-\mathrm{N}}, \mu_{\mathrm{B}}$ & 4.21 & +3.80 & 0.00 & 4.19 & 3.56 & 0.00 & 5.02 & \\
\hline$\mu_{\mathrm{Fe}(\mathrm{II})-\mathrm{C}}, \mu_{\mathrm{B}}$ & $1.27-1.28$ & -0.05 & 0.00 & $1.10-1.11$ & 0.06 & 0.00 & 0.8 & \\
\hline$\mu_{\mathrm{N}}, \mu_{\mathrm{B}}$ & $0.06-0.07$ & 0.03 & 0.00 & $0.05-0.09$ & 0.02 & 0.00 & & \\
\hline$\mu_{\mathrm{C}}, \mu_{\mathrm{B}}$ & -0.01 & 0.00 & 0.00 & $-0.02-0.01$ & 0.01 & 0.00 & & \\
\hline$\mu_{\mathrm{K}}, \mu_{\mathrm{B}}$ & & 0.00 & 0.00 & & 0.00 & 0.00 & & \\
\hline
\end{tabular}

${ }^{a} E_{\mathrm{hs}-\mathrm{ls}}-E_{\mathrm{ls}-\mathrm{ls}}$ is a measure if and how much the hs-ls ground state is stabilized over the diamagnetic ls-ls state. The band gap $\Delta E_{\mathrm{g}}$ corresponds to $\mathrm{Fe}-\mathrm{C} \mathrm{t}_{2 \mathrm{~g}}-\mathrm{Fe}-\mathrm{N} \mathrm{t}_{2 \mathrm{~g}}$. CFSE $\mathrm{Fe}_{\mathrm{Fe}(\mathrm{III})-\mathrm{N}}$ is the energy difference of $\mathrm{Fe}(\mathrm{III})-\mathrm{N}_{2 \mathrm{~g}}$ and $\mathrm{e}_{\mathrm{g}}$ in BG.

Both the $\mathrm{Fe}(\mathrm{II})-\mathrm{C}_{2 \mathrm{~g}}$ and $\mathrm{Fe}(\mathrm{III})-\mathrm{N}_{2 \mathrm{~g}}$ peaks contain a considerable amount of nitrogen $\mathrm{p}$-density.

In summary, although hybrid functionals provide a more consistent approach than GGA+U, they are often disfavored due to their huge computational cost. Furthermore, they may overcorrect the DFT-inherent self-interaction error. In the further discussion we will compare the applicability of HSE03 and compare it to GGA+U. For the DFT assessment of PB-type structures, we choose the PBEsol functional with an effective $U$ correction of $5.5 \mathrm{eV}$, as it gives good results for the band gaps and the lattice constant.

\subsection{Different Redox Forms: Prussian White and Berlin}

Green. The PB analogues BG and PW also have two low-lying magnetic configurations hs-ls and ls-ls, which are shown in Figure 7a. We calculated both spin states with varying $U^{\text {eff }}$ and compared their energy differences $E_{\mathrm{hs}-\mathrm{ls}}-E_{\mathrm{ls}-\mathrm{ls}}$ in Figure $7 \mathrm{~b}$.

A summary of results for the most likely spin configurations of all three redox forms BG, PB, and PW for HSE03, as well as PBEsol+U $\left(U^{\text {eff }}=5.5 \mathrm{eV}\right)$, is shown in Table 2. For a $U^{\text {eff }}>$ $3.3 \mathrm{eV}$ BG is stabilized in a hs-ls configuration, which is also found in experimental studies ${ }^{34,37}$ and hybrid calculations (Table 2). When oxidizing PB to BG, an electron is removed from the C-coordinated iron center (ls $\mathrm{Fe}$ (II)-C), leaving a hole in one of the electron $t_{2 g}$ orbitals and remaining in a ls state due to the strong ligand field exerted by the cyanide $\mathrm{C}$. The hs $\mathrm{Fe}(\mathrm{III})-\mathrm{N}$ center is hardly influenced upon reduction from $\mathrm{PB}$ to BG. This is also seen in the invariance of the $\mathrm{Fe}-\mathrm{N}$ bond length $d(\mathrm{Fe}-\mathrm{N})$ (Table 2). Hence, hs-ls $\mathrm{BG}$ is the correct magnetic ground state. On the contrary, hs-ls $\mathrm{PW}$ is never stabilized by PBEsol, with $U^{\text {eff }}$ varying from 0 to $9 \mathrm{eV}$. Although higher $U^{\text {eff }}$ parameters might yield to a stabilization of the hs-ls configuration, they are unphysical and are therefore avoided. Experimental results, however, show magnetic behavior ${ }^{36,37}$ and conduction, ${ }^{38}$ which are both absent in diamagnetic $(S=0)$ and insulating ls-ls PW. With HSE03, a slight stabilization of $0.10 \mathrm{eV}$ of hs-ls PW is found. With DFT and hybrid calculations leading to contradictory results, the true electronic ground state of PW cannot be clearly determined. It is expected that both hs-ls and ls-ls configurations lie close in energy and that the hs-ls state prevails at room temperature due to entropic 

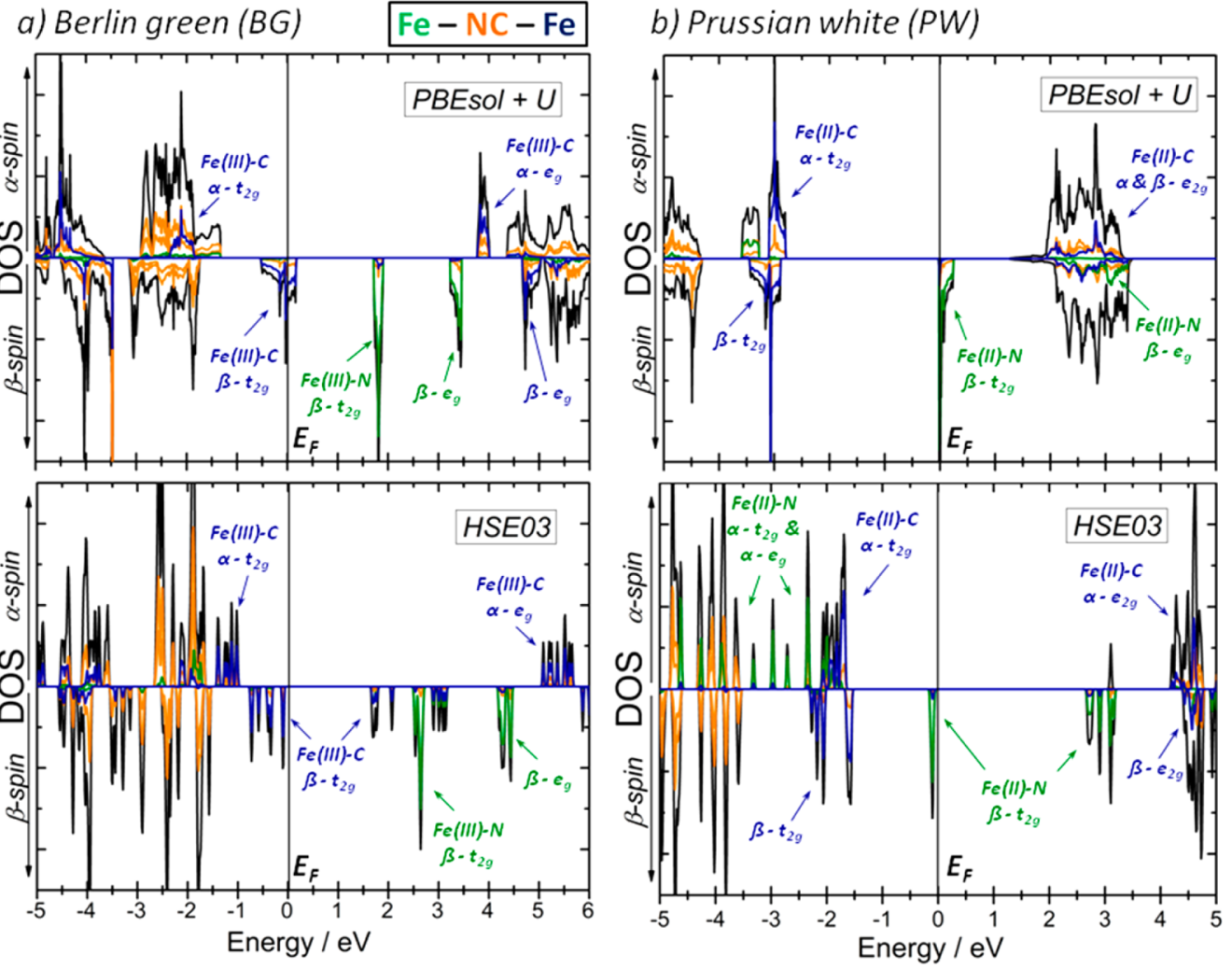

Figure 8. Projected DOS for all atoms in (a) hs-ls BG and (b) hs-ls PW calculated with PBEsol+U and HSE03.

stabilization, as it is predicted by Kepp et al. ${ }^{63}$ To facilitate comparison with hs-ls $\mathrm{PB}$, and because it is in accordance with experimental results, we will assume a hs-ls configuration in the following discussion.

The structural parameters of both BG and PW (hs-ls) are similar to those of PB. Oxidation (reduction) from $\mathrm{PB}$ to $\mathrm{BG}$ (PW), removes (adds) an electron from (to) the effectively nonbonding $\mathrm{t}_{2 \mathrm{~g}}$ orbital of $\mathrm{Fe}(\mathrm{II})-\mathrm{C}(\mathrm{Fe}(\mathrm{III})-\mathrm{N})$, thus not altering the bond length. Upon reduction to PW the lattice expands by $\sim 1 \%$. Small structural changes may be due to the insertion or removal of the cation, which will be discussed later in the text. The charges and, more significantly, the magnetizations on the $\mathrm{Fe}$ centers reflect two distinct reduction steps, from BG to $\mathrm{PB}$ and from $\mathrm{PB}$ to $\mathrm{PW}$ (Tables 1 and 2). When $\mathrm{BG}$ ( $\left.\mathrm{Fe}(\mathrm{III})\left[\mathrm{Fe}(\mathrm{III})(\mathrm{CN})_{6}\right]\right)$ is reduced to $\mathrm{PB}(\mathrm{KFe}(\mathrm{III})[\mathrm{Fe}(\mathrm{II})$ $\left.\left.(\mathrm{CN})_{6}\right]\right)$, an electron is added to $\mathrm{Fe}(\mathrm{III})-\mathrm{C}$, filling the $\mathrm{t}_{2 \mathrm{~g}}$ shell; hence, the positive charges and magnetic moments on $\mathrm{Fe}-\mathrm{C}$ decrease. When $\mathrm{PB}\left(\mathrm{KFe}(\mathrm{III})\left[\mathrm{Fe}(\mathrm{II})(\mathrm{CN})_{6}\right]\right)$ is reduced to PW $\left(\mathrm{K}_{2} \mathrm{Fe}(\mathrm{II})\left[\mathrm{Fe}(\mathrm{II})(\mathrm{CN})_{6}\right]\right)$, an electron is added to $\mathrm{Fe}(\mathrm{III})-\mathrm{N}$, and the positive charges and magnetic moments on $\mathrm{Fe}-\mathrm{N}$ decrease. Nevertheless, the charges obtained with PBEsol+U may not show this behavior being due to the $U$ correction localizing too much charge on $\mathrm{Fe}-\mathrm{C}$. For PW no CFSE is given, since the extra electron lifts the degeneracy of the $\mathrm{Fe}(\mathrm{II})-\mathrm{N}_{2 \mathrm{~g}}$ $d$-orbital, and therefore no clear gap between $t_{2 g}$ and $e_{g}$ can be distinguished.

Figure 8 shows the DOS calculated with PBEsol+U and HSE03 for both compounds BG and PW (hs-ls). Also here a descent in symmetry is visible, with both $t_{2 g}$ and $e_{g}$ sets being no longer degenerate and split in multiple bands. When PB is oxidized to $B G$, one electron is removed from the $\mathrm{Fe}-\mathrm{C}_{2 \mathrm{~g}}$ set; hence, the $\mathrm{Fe}(\mathrm{III})-\mathrm{C}_{2 \mathrm{~g}}$ band is shifted to higher energy, which can be seen in Figure $8 \mathrm{a}$. For PBEsol+U this $\mathrm{Fe}(\mathrm{III})-\mathrm{C} \beta-\mathrm{t}_{2 \mathrm{~g}}$ band overlaps with the Fermi level and, thus, results in a halfmetallic state. ${ }^{30}$ HSE03, on the contrary, indicates insulating behavior with a band gap of $1.59 \mathrm{eV}$. This comes from the fact that the $\mathrm{Fe}(\mathrm{III})-\mathrm{C} \beta$ - $_{2 \mathrm{~g}}$ level is split into narrow distinct bands, with the unoccupied $\beta$ - $\mathrm{t}_{2 \mathrm{~g}}$ spin orbital lying well above the Fermi level and the two occupied $\beta$ - $\mathrm{t}_{2 \mathrm{~g}}$ spin orbitals just below (Figure $8 \mathrm{~b}$ ). Recent experimental studies on the conductivity of BG show an inverse resistance dependence on the temperature as opposed to metallic behavior. ${ }^{35}$ Therefore, the PBEsol+U prediction of BG being a half-metal is insufficient. However, the large band gap of $1.59 \mathrm{eV}$ predicted by HSE03 excludes thermally activated conduction. A different conduction mechanism might take place, such as, for example, an electron-hopping mechanism, which was proposed by Pajerowski et al. ${ }^{35}$ The splitting of occupied and unoccupied $\beta$ - $\mathrm{t}_{2 \mathrm{~g}}$ spin orbitals, as shown by HSE03, is believed to be qualitatively correct but exaggerated. The high amount of Hartree-Fock exchange in the hybrid functional probably leads to an overestimation of the spin-pairing energy for this system. A similar effect is seen in the electronic structure of PW (Figure 8c,d). Upon reduction of PB (hs-ls) to PW (hs-ls) an extra electron with opposite spin is incorporated in the $t_{2 g}$ set of $\mathrm{Fe}-\mathrm{N}$, shifting the $\beta$ - $\mathrm{t}_{2 \mathrm{~g}}$ band toward lower energy. In the case of PBEsol+U the $\mathrm{Fe}(\mathrm{II})-\mathrm{N} \beta-\mathrm{t}_{2 \mathrm{~g}}$ band overlaps with the Fermi level, while it is split into occupied and unoccupied $\beta$ - $\mathrm{t}_{2 \mathrm{~g}}$ spin orbitals with the hybrid calculation, giving rise to a large band gap of $2.62 \mathrm{eV}$. Again, HSE03 exaggerates the spin-pairing energy, therefore giving unphysical wide band gaps, which are opposed to the experimentally observed conduction. ${ }^{38}$

In both cases, neither HSE hybrid functionals nor GGA+U give a complete description of the accurate electronic structure. Although PBEsol $+U^{\text {eff }}$ with $U^{\text {eff }}=5.5 \mathrm{eV}$ provides a good description of the magneto-electronics of $\mathrm{PB}$, it is not adequate for its redox forms, in which the electronic environment is changed. ${ }^{64}$ 

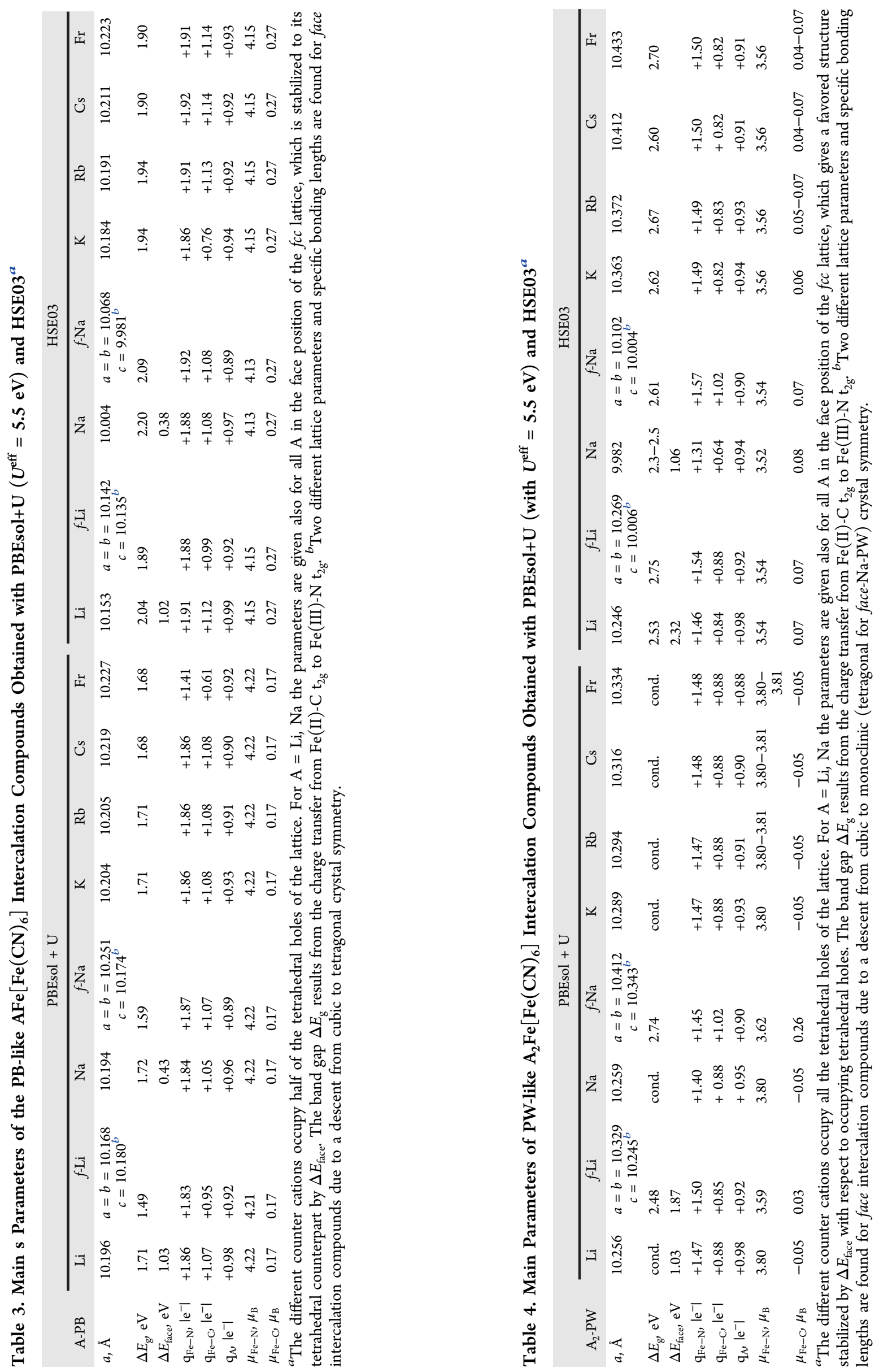
a)

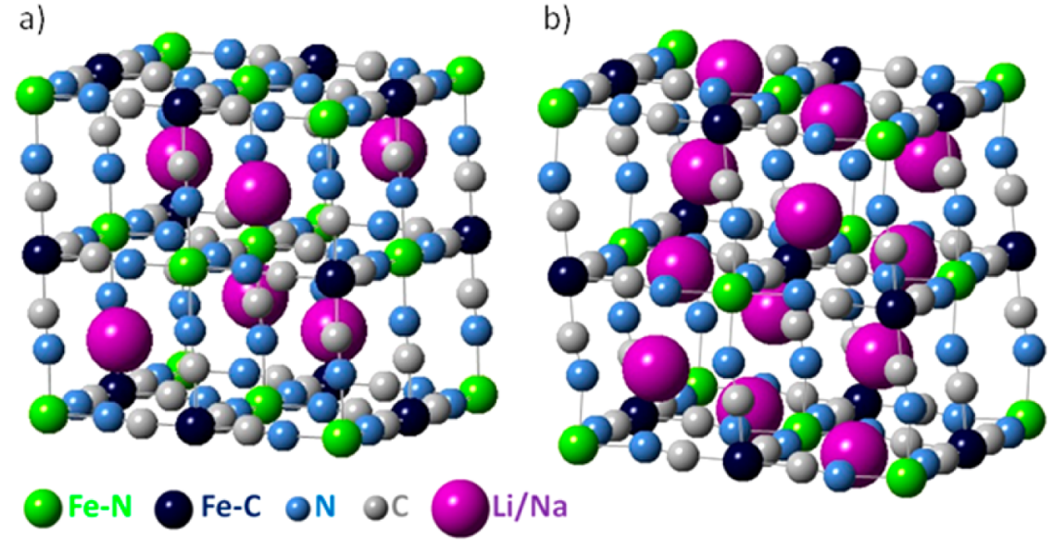

c)

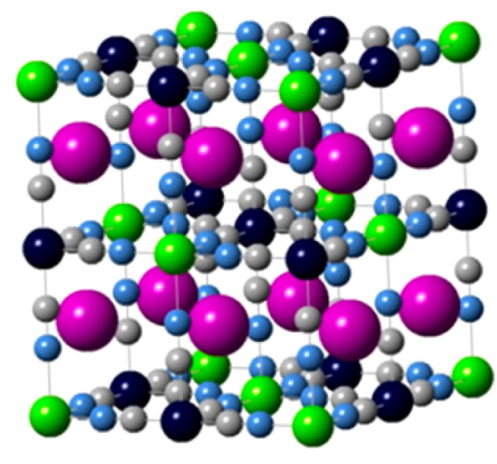

Figure 9. Intercalation compounds with small cations Li and Na: Crystal structures of the (a) face Li-PB and face Na-PB, (b) face Li-PW, and (c) face Na-PW.

It is seen that, while GGA overestimates electron delocalization and leads to large broadening of bands, HSE over corrects the self-interaction error and thus exaggerates the band splitting.

3.3. Database of Prussian White-Related Compounds with Different Alkali Atoms. To set up a complete database, as well as to test the influence of different cations on different parameters, we incorporated all alkali cations ( $\mathrm{Li}, \mathrm{Na}, \mathrm{K}$, $\mathrm{Rb}, \mathrm{Cs}, \mathrm{Fr}$ ) in PB-like (AFe(III) $\left[\mathrm{Fe}(\mathrm{II})(\mathrm{CN})_{6}\right]$ ) (Figure $2 \mathrm{~b}$ ) and PW-like $\left(\mathrm{A}_{2} \mathrm{Fe}(\mathrm{II})\left[\mathrm{Fe}(\mathrm{II})(\mathrm{CN})_{6}\right]\right.$ ) (Figure $2 \mathrm{c}$ ) structures and calculated their structural and electronic properties with both PBEsol+U $\left(U^{\text {eff }}=5.5 \mathrm{eV}\right)$ and HSE03 functionals (Tables 3 and 4).

For the smaller alkali metal cations, $\mathrm{Li}^{+}$and $\mathrm{Na}^{+}$, it was found that the face positions in the lattice, instead of the tetrahedral holes, are preferred (Figure 9). The resulting, more stable intercalation compounds are labeled $f$-Li-PB, $f$-Li-PW and $f$-Na$\mathrm{PB}, f$-Na-PW, respectively, and are listed in Tables 3 and 4 as well. The larger alkali cations $(\mathrm{K}, \mathrm{Rb}, \mathrm{Cs}, \mathrm{Fr})$ do occupy the tetrahedral holes in the ground state. For potassium, for instance, $\mathrm{K}-\mathrm{PB}$ is stabilized by $0.26 \mathrm{eV}(\mathrm{PBEsol}+\mathrm{U})$ with respect to $f$-K-PB. In the case of $f$-Li-PW, the structure was found to be more stable $(\Delta E=1.03 \mathrm{eV}$ with $\mathrm{PBEsol}+\mathrm{U})$, if all the cations lie in diagonal $\{222\}$ planes (Figure $9 b$ ), instead of in parallel $\{100\}$ and $\{200\}$ lattice planes (Figure 9c), while the opposite is true for face Na-PW ( $\Delta E=0.02 \mathrm{eV}$ with PBEsol+U). It is remarked that other positions, different than lattice faces or tetrahedral holes, may also be envisaged for $\mathrm{Li}^{+}$and $\mathrm{Na}^{+}$, as did Ling et al., ${ }^{32}$ but this lies beyond the scope of this article.

$\mathrm{Li}$ and $\mathrm{Na}$ ionic radii are sufficiently small to occupy the square-planar holes that are spanned by four Fe-centers. Optimization of $f$-PB and $f$-PW structures leads to a distortion of cubic symmetry; hence, two different lattice parameters and bond lengths can be found. This is due to the negatively charged $\mathrm{N}$-site of the cyanide ligand bending toward the positively charged countercation and thus leading to a stabilization of the distorted structure. In contrast, larger metals produce tetrahedral intercalation compounds. Along the series, the lattice expands as the alkali cation size increases (Figure 10). The $\mathrm{Fe}-\mathrm{N}$ and $\mathrm{Fe}-\mathrm{C}$ bonds lengthen, while the $\mathrm{C}-\mathrm{N}$ distance stays the same (Supporting Information Tables S6-S9). The effect of the lattice expansion, which is of the order of $1 \%$, has a higher impact on PW-like than PB-like structures, since all the tetrahedral holes are occupied (Figure 2). For the HSE03 calculations, this effect is more pronounced. Sodium intercalated compounds Na-PB and Na-PW seem to be exceptions, since its

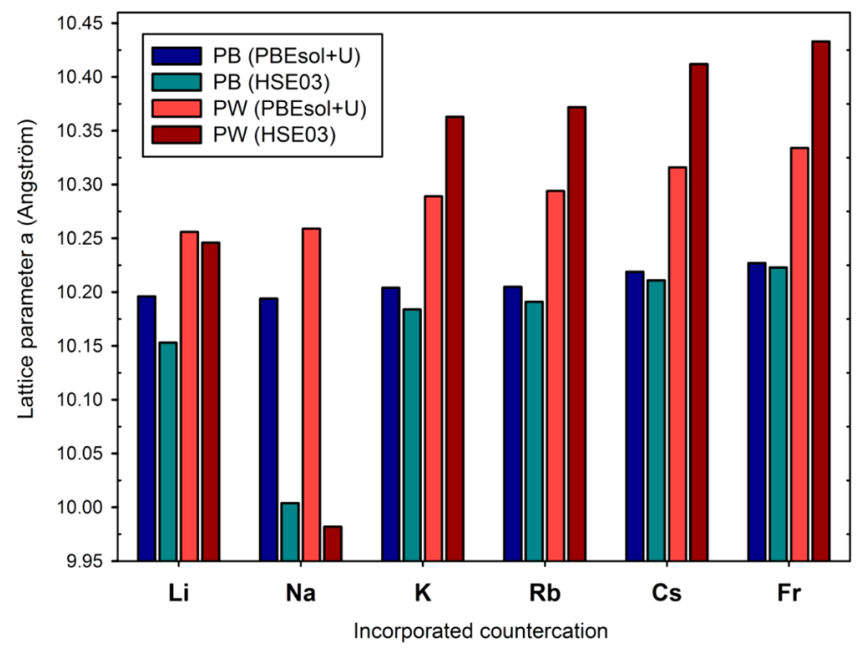

Figure 10. Variation of lattice parameter for different countercations (incorporated in the tetrahedral holes) of the PB and PW lattice for PBEsol $+\mathrm{U}$ and HSE03 functionals.

lattice parameter is equal (PBEsol+U) or even decreased (HSE03) compared to $\mathrm{Li}-\mathrm{PB}$ or $\mathrm{Li}-\mathrm{PW}$, respectively.

The charges and magnetic moments are not significantly affected by the incorporation of the cation, if tetrahedral, since the cation is not expected to actively participate in the electronic structure (see Tables 3, 4, and S6-S9). The charge of the alkali metal itself decreases slightly from $\mathrm{Li}$ to Cs, which reflects the decreasing charge concentration $(q / r)$ of the ion. If the cation is placed at the faces $(f-\mathrm{PB}$ and $f$-PW) the ionic charges vary, which is attributed to the significant structural distortion of the lattice. Moreover, the cationic charge decreases by $\sim 0.1 \mathrm{le}^{-} \mathrm{l}$, which indicates an interaction between the $\mathrm{CN}$ ligand and the alkali metal when it is placed at the faces of the lattice. In all cases, the magnetic moments remain effectively unchanged (Supporting Information Tables S6-S9).

Regarding PBEsol+U calculations, the band gap and the CFSE do not vary throughout the (tetrahedral) series. In HSE03 simulations, a small decrease of the band gap of $\sim 0.1 \mathrm{eV}$ is seen. On the one hand, Rosseinsky et al. observed a change in band gaps and attributed this to cation-lattice interactions. ${ }^{65}$ On the other hand, Wojdel et al. reported a decrease of the band gap from $\mathrm{K}^{+}$to $\mathrm{Cs}^{+}$, suggesting a lattice expansion effect. ${ }^{29}$ Our results seem to favor the latter, geometric, effect. In the case of $\mathrm{Na}-\mathrm{PB}$ (HSE03), the lattice is contracted by $\sim 2 \%$, and the band 
gap increased by $\sim 20 \%$ compared to $\mathrm{K}-\mathrm{PB}$, which is supporting this assumption. Moreover, this effect of the geometry on the band gap can be observed in $f-\mathrm{Li}-\mathrm{PB}$ and $f-\mathrm{Na}-\mathrm{P}$, where the lattice is distorted in the plane, in which the cations lie, leading to a decrease in band gap and CFSE.

The effect on the electronic structure is presented best by the DOS, which is shown for $\mathrm{Li}-\mathrm{PB}, f-\mathrm{Li}-\mathrm{PB}$, and Fr-PB (Figure 11)
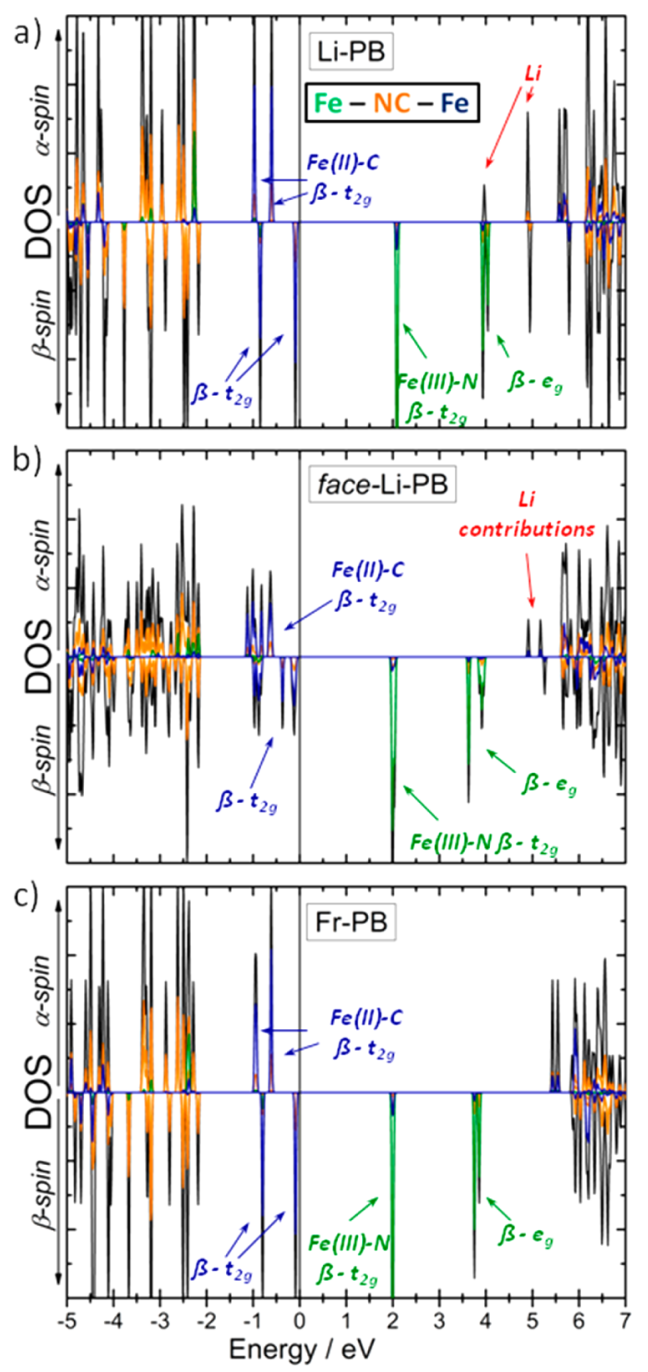

Figure 11. Projected DOS for the intercalated PB-type compounds Li-PB (a), face-Li-PB (b), and Fr-PB (c) calculated with HSE03.

and which was calculated by HSE03. Li-PB and Fr-PB have very similar electronic structures, again indicating that there is no major effect of the cation on the electronic structure. However, there is some antibonding cation-ligand interaction, which is shifted to higher energies with increasing cation size. The electronic structure for $f$-PB and $f$-PW, with cations on the lattice faces, varies significantly, which can be seen in Figure $11 \mathrm{~b}$ for $f$-Li-PB. Because of the structural distortion, the former (almost-) degeneracy of orbitals is lifted, and electronic states are further split into several parts. This also influences the CFSE, which is smaller for $f$-PB and $f$-PW, respectively, because the former $\mathrm{t}_{2 \mathrm{~g}}$ and $\mathrm{e}_{\mathrm{g}}$ sets of $\mathrm{Fe}-\mathrm{N}$ are split into smaller bands and spread apart (Figure 11b).

\section{CONCLUSIONS}

DFT has been shown to be insufficient in describing the correct electronic ground state of $\mathrm{PB}$ and its related analogues due to many low-lying charge transfer states and magnetic configurations. GGA+U seems to be an adequate compromise to accurately assess localized charges and magnetizations on the transition-metal centers with relatively small computational effort. Nonetheless, GGA+U calculations must be treated very carefully, as they are empirically fitted to represent the experimental data of $\mathrm{KFe}(\mathrm{III})\left[\mathrm{Fe}(\mathrm{II})(\mathrm{CN})_{6}\right] \mathrm{PB}$ and are not universally transferable to its derivatives. For practical use GGA+U gives good initial estimates for electronic and geometrical properties and serves as a reasonable comparison between related compounds. Hybrid functionals, such as HSE03, are clearly more accurate but also dramatically more expensive. Even hybrid functionals, however, might over correct the electronic selfinteraction error and therefore overestimate band gaps and band splittings.

The insertion of cations leads to a small expansion of the lattice, if cations are inserted into the tetrahedral holes of the structure. The relative lattice expansion increases with cationic size. The smaller ions $\mathrm{Li}^{+}$and $\mathrm{Na}^{+}$give unstable structures when placed in tetrahedral holes of the lattice and prefer to move to the faces of the structure. The electronic structure is not significantly influenced when varying the type of countercation. It changes, however, when oxidizing or reducing the iron centers, thus along the green, blue, white series. The oxidized and reduced forms of $\mathrm{PB}$, do show conducting behavior being due to a shift in Fermi level. Neither PBEsol+U nor HSE03 has shown to correctly describe the conducting behavior of those compounds, but the model for the ideal lattice might be a potential source for the discrepancy.

In summary, we have identified the challenges ahead in the modeling of PB-type compounds both increasing the countercation and its concentration. The modeling of the ideal lattice gives some hints pointing at the minimum computational setup to reproduce the geometries and electronic structures, but the role of impurities, partial occupancies, and other deviations from the ideal model are still ahead. A complete full database for all the compounds in the family is presented.

\section{ASSOCIATED CONTENT}

\section{Supporting Information}

The Supporting Information is available free of charge on the DOI: 10.1021 /acs.inorgchem.6b02200.

Listings of extended functional tests, influence of Hubbard $U$ parameter on structural and electronic parameters, energies of different magnetic configurations, complete tables of all structural and electronic parameters for $\mathrm{PB}$ and $\mathrm{PW}$ derivatives with different countercations (PDF)

\section{AUTHOR INFORMATION}

\section{Corresponding Author}

*E-mail: nlopez@iciq.es.

\section{ORCID}

José Ramón Galán-Mascarós: 0000-0001-7983-9762 Núria López: 0000-0001-9150-5941

\section{Notes}

The authors declare no competing financial interest. The present calculations have been uploaded to the ioChemBD database ${ }^{66}$ under DOI: 10.19061/iochem-bd-1-20. 


\section{ACKNOWLEDGMENTS}

This research has been supported by the MINECO projects (CTQ2015-68770-R and CTQ2015-71287-R). We also acknowledge BSC-CNS for providing generous computational resources. F.S.H. thanks La Caixa-Severo Ochoa for a predoctoral grant.

\section{REFERENCES}

(1) DeLongchamp, D. M.; Hammond, P. T. Multiple-Color Electrochromism from Layer-by-Layer-Assembled Polyaniline/Prussian Blue Nanocomposite Thin Films. Chem. Mater. 2004, 16, 47994805 .

(2) Wang, L.; Song, J.; Qiao, R. M.; Wray, L. A.; Hossain, M. A.; Chuang, Y. D.; Yang, W. L.; Lu, Y. H.; Evans, D.; Lee, J. J.; Vail, S.; Zhao, X.; Nishijima, M.; Kakimoto, S.; Goodenough, J. B. Rhombohedral Prussian White as Cathode for Rechargeable Sodium-Ion Batteries. J. Am. Chem. Soc. 2015, 137, 2548-2554.

(3) Kundu, D.; Talaie, E.; Duffort, V.; Nazar, L. F. The Emerging Chemistry of Sodium Ion Batteries for Electrochemical Energy Storage. Angew. Chem., Int. Ed. 2015, 54, 3431-3448.

(4) Goberna-Ferron, S.; Hernandez, W. Y.; Rodriguez-Garcia, B.; Galan-Mascaros, J. R. Light-Driven Water Oxidation with Metal Hexacyanometallate Heterogeneous Catalysts. ACS Catal. 2014, 4, 1637-1641.

(5) Pintado, S.; Goberna-Ferron, S.; Escudero-Adan, E. C.; GalanMascaros, J. R. Fast and Persistent Electrocatalytic Water Oxidation by Co-Fe Prussian Blue Coordination Polymers. J. Am. Chem. Soc. 2013, 135, 13270-13273.

(6) Karyakin, A. A. Prussian Blue and Its Analogues: Electrochemistry and Analytical Applications. Electroanalysis 2001, 13, 813819.

(7) Yasutaka, T.; Kawamoto, T.; Kawabe, Y.; Sato, T.; Sato, M.; Suzuki, Y.; Nakamura, K.; Komai, T. Rapid Measurement of Radiocesium in Water Using a Prussian Blue Impregnated Nonwoven Fabric: Fukushima Npp Accident Related. J. Nucl. Sci. Technol. 2013, 50, 674-681.

(8) Zhang, W.; Hu, S.; Yin, J.-J.; He, W.; Lu, W.; Ma, M.; Gu, N.; Zhang, Y. Prussian Blue Nanoparticles as Multienzyme Mimetics and Reactive Oxygen Species Scavengers. J. Am. Chem. Soc. 2016, 138, $5860-5865$

(9) Sato, O.; Iyoda, T.; Fujishima, A.; Hashimoto, K. Photoinduced Magnetization of a Cobalt-Iron Cyanide. Science 1996, 272, 704-705.

(10) Sato, O.; Kawakami, T.; Kimura, M.; Hishiya, S.; Kubo, S.; Einaga, Y. Electric-Field-Induced Conductance Switching in FeCo Prussian Blue Analogues. J. Am. Chem. Soc. 2004, 126, 13176-13177.

(11) Ferlay, S.; Mallah, T.; Ouahes, R.; Veillet, P.; Verdaguer, M. A Room-Temperature Organometallic Magnet Based on Prussian Blue. Nature 1995, 378, 701-703.

(12) Buser, H. J.; Ludi, A. Single-Crystal Study of Prussian Blue $\mathrm{Fe}_{4}\left[\mathrm{Fe}(\mathrm{CN})_{6}\right]_{2} 14 \mathrm{H}_{2} \mathrm{O}$. J. Chem. Soc., Chem. Commun. 1972, 12991299.

(13) Buser, H. J.; Schwarzenbach, D.; Petter, W.; Ludi, A. CrystalStructure of Prussian Blue - $\mathrm{Fe}_{4}\left[\mathrm{Fe}(\mathrm{CN})_{6}\right]_{3} x \mathrm{H}_{2} \mathrm{O}$. Inorg. Chem. 1977, $16,2704-2710$.

(14) Herren, F.; Fischer, P.; Ludi, A.; Halg, W. Neutron-Diffraction Study of Prussian Blue, $\mathrm{Fe}_{4}\left[\mathrm{Fe}(\mathrm{CN})_{6}\right]_{3} x \mathrm{H}_{2} \mathrm{O}$ - Location of WaterMolecules and Long-Range Magnetic Order. Inorg. Chem. 1980, 19, 956-959.

(15) The inverse redox form ferrous ferricyanide $\mathrm{KFe}(\mathrm{II})[\mathrm{Fe}(\mathrm{III})$ $(\mathrm{CN})_{6}$ ], also called Turnbulls blue, was not observed. Although in solution the ferrous $\mathrm{Fe}(\mathrm{II})$ cation and ferricyanide $\left[\mathrm{Fe}(\mathrm{III})(\mathrm{CN})_{6}\right]$ anions are more stable, ferric ferrocyanide $\mathrm{KFe}(\mathrm{III})\left[\mathrm{Fe}(\mathrm{II})(\mathrm{CN})_{6}\right]$ is the more stable redox form in the solid state.

(16) Cosgrove, J. G.; Collins, R. L.; Murty, D. S. Preparation of Ferrous Ferricyanide (Not Turnbulls Blue). J. Am. Chem. Soc. 1973, 95, 1083.

(17) Hansen, L. D.; Litchman, W. M.; Daub, G. H. Turnbulls Blue and Prussian Blue - $\mathrm{KFe}\left[\mathrm{Fe}(\mathrm{CN})_{6}\right]$. J. Chem. Educ. 1969, 46, 46-46.
(18) Ito, A.; Suenaga, M.; Ono, K. Mossbauer Study of Soluble Prussian Blue Insoluble Prussian Blue and Turnbulls Blue. J. Chem. Phys. 1968, 48, 3597-3599.

(19) Brunschwig, B. S.; Creutz, C.; Sutin, N. Optical Transitions of Symmetrical Mixed-Valence Systems in the Class Ii-Iii Transition Regime. Chem. Soc. Rev. 2002, 31, 168-184.

(20) Davidson, D.; Welo, L. A. The Nature of Prussian Blue. J. Phys. Chem. 1927, 32, 1191-1196.

(21) Ruiz, E.; Rodriguez-Fortea, A.; Alvarez, S.; Verdaguer, M. Is It Possible to Get High $\mathrm{T}_{\mathrm{C}}$ Magnets with Prussian Blue Analogues? A Theoretical Prospect. Chem. - Eur. J. 2005, 11, 2135-2144.

(22) Day, P.; Herren, F.; Ludi, A.; Gudel, H. U.; Hulliger, F.; Givord, D. Valence Delocalization in Prussian Blue $\mathrm{Fe}_{4}(\mathrm{III})[\mathrm{Fe}(\mathrm{II})$ $\left.(\mathrm{CN})_{6}\right]_{3} \cdot \mathrm{XH}_{2} \mathrm{O}$, by Polarized Neutron-Diffraction. Helv. Chim. Acta 1980, 63, 148-153.

(23) Mayoh, B.; Day, P. Charge-Transfer in Mixed-Valence Solids 0.8. Contribution of Valence Delocalization to Ferromagnetism of Prussian Blue. J. Chem. Soc., Dalton Trans. 1976, 1483-1486.

(24) Middlemiss, D. S.; Wilson, C. C. Ferromagnetism and Spin Transitions in Prussian Blue: A Solid-State Hybrid Functional Study. Phys. Rev. B: Condens. Matter Mater. Phys. 2008, 77, 1-13.

(25) Robin, M. B. Color and Electronic Configurations of Prussian Blue. Inorg. Chem. 1962, 1, 337-342.

(26) Gmelin, L. Gmelins Handbuch Der Anorganischen Chemie; Eisen, B., Ed.; Heidelberg, Germany, 1932.

(27) Wojdel, J. C.; de P. R. Moreira, I.; Bromley, S. T.; Illas, F. On the Prediction of the Crystal and Electronic Structure of MixedValence Materials by Periodic Density Functional Calculations: The Case of Prussian Blue. J. Chem. Phys. 2008, 128, 044713-1-0447139.

(28) Wojdel, J. C.; Bromley, S. T. Efficient Calculation of the Structural and Electronic Properties of Mixed Valence Materials: Application to Prussian Blue Analogues. Chem. Phys. Lett. 2004, 397, 154-159.

(29) Wojdel, J. C.; Bromley, S. T. Band Gap Variation in Prussian Blue Via Cation-Induced Structural Distortion. J. Phys. Chem. B 2006, 110, 24294-24298.

(30) Wojdel, J. C.; Moreira, I. D. R.; Bromley, S. T.; Illas, F. Prediction of Half-Metallic Conductivity in Prussian Blue Derivatives. J. Mater. Chem. 2009, 19, 2032-2036.

(31) Wojdel, J. C.; Moreira, I. D. R.; Illas, F. Periodic Density Functional Theory Study of Spin Crossover in the Cesium Iron Hexacyanochromate Prussian Blue Analog. J. Chem. Phys. 2009, 130, 014702 .

(32) Ling, C.; Chen, J. J.; Mizuno, F. First-Principles Study of Alkali and Alkaline Earth Ion Intercalation in Iron Hexacyanoferrate: The Important Role of Ionic Radius. J. Phys. Chem. C 2013, 117, 2115821165.

(33) Wojdel, J. C. First Principles Calculations on the Influence of Water-Filled Cavities on the Electronic Structure of Prussian Blue. J. Mol. Model. 2009, 15, 567-571.

(34) Kumar, A.; Yusuf, S. M.; Keller, L. Structural and Magnetic Properties of $\mathrm{Fe}\left[\mathrm{Fe}(\mathrm{CN})_{6}\right] .4 \mathrm{H}_{2} \mathrm{O}$. Phys. Rev. B: Condens. Matter Mater. Phys. 2005, 71, 1-7.

(35) Pajerowski, D. M.; Watanabe, T.; Yamamoto, T.; Einaga, Y. Electronic Conductivity in Berlin Green and Prussian Blue. Phys. Rev. B: Condens. Matter Mater. Phys. 2011, 83, 1-4.

(36) Hu, M.; Jiang, J. S. Facile Synthesis of Air-Stable Prussian White Microcubes Via a Hydrothermal Method. Mater. Res. Bull. 2011, 46, 702-707.

(37) Maer, K.; Beasley, M. L.; Collins, R. L.; Milligan, W. O. Structure of Titanium-Iron Cyanide Complexes. J. Am. Chem. Soc. 1968, 90, 3201-3208.

(38) Xidis, A.; Neff, V. D. On the Electronic Conduction in Dry Thin-Films of Prussian Blue, Prussian Yellow, and Everitt Salt. J. Electrochem. Soc. 1991, 138, 3637-3642.

(39) Kresse, G.; Furthmuller, J. Efficient Iterative Schemes for Ab Initio Total-Energy Calculations Using a Plane-Wave Basis Set. Phys. Rev. B: Condens. Matter Mater. Phys. 1996, 54, 11169-11186. 
(40) Hafner, J.; Kresse, G. The Vienna Ab-Initio Simulation Program Vasp: An Efficient and Versatile Tool for Studying the Structural, Dynamic, and Electronic Properties of Materials; Plenum Press Div Plenum Publishing Corp: New York, 1997; pp 69-82.

(41) Perdew, J. P.; Burke, K.; Ernzerhof, M. Generalized Gradient Approximation Made Simple. Phys. Rev. Lett. 1996, 77, 3865-3868.

(42) Perdew, J. P.; Burke, K.; Ernzerhof, M. Generalized Gradient Approximation Made Simple (Vol 77, Pg 3865, 1996). Phys. Rev. Lett. 1997, 78, 1396-1396.

(43) Perdew, J. P.; Ruzsinszky, A.; Csonka, G. I.; Vydrov, O. A.; Scuseria, G. E.; Constantin, L. A.; Zhou, X. L.; Burke, K. Restoring the Density-Gradient Expansion for Exchange in Solids and Surfaces. Phys. Rev. Lett. 2009, 102, 1-4.

(44) Zhang, Y. K.; Yang, W. T. Comment on "Generalized Gradient Approximation Made Simple". Phys. Rev. Lett. 1998, 80, 890-890.

(45) Perdew, J. P.; Chevary, J. A.; Vosko, S. H.; Jackson, K. A.; Pederson, M. R.; Singh, D. J.; Fiolhais, C. Atoms, Molecules, Solids, and Surfaces - Applications of the Generalized Gradient Approximation for Exchange and Correlation. Phys. Rev. B: Condens. Matter Mater. Phys. 1992, 46, 6671-6687.

(46) Perdew, J. P.; Chevary, J. A.; Vosko, S. H.; Jackson, K. A.; Pederson, M. R.; Singh, D. J.; Fiolhais, C. Atoms, Molecules, Solids, and Surfaces - Applications of the Generalized Gradient Approximation for Exchange and Correlation (Vol 46, Pg 6671, 1992). Phys. Rev. B: Condens. Matter Mater. Phys. 1993, 48, 4978-4978.

(47) Mattsson, A. E.; Armiento, R.; Paier, J.; Kresse, G.; Wills, J. M.; Mattsson, T. R. The Am05 Density Functional Applied to Solids. J. Chem. Phys. 2008, 128, 084714.

(48) Anisimov, V. I.; Aryasetiawan, F.; Lichtenstein, A. I. FirstPrinciples Calculations of the Electronic Structure and Spectra of Strongly Correlated Systems: The LDA+U Method. J. Phys.: Condens. Matter 1997, 9, 767-808.

(49) Dudarev, S. L.; Botton, G. A.; Sutton, A. P. Electron Energy Loss Spectra and the Structural Stability of Oxides with Strongly Correlated Electrons; Iop Publishing Ltd: Bristol, England, 1998, 613-614.

(50) Parr, R. G.; Yang, W. Density-Functional Theory of Atoms and Molecules; Oxford University Press: Oxford, England, 1989.

(51) Heyd, J.; Scuseria, G. E.; Ernzerhof, M. Hybrid Functionals Based on a Screened Coulomb Potential. J. Chem. Phys. 2003, 118, $8207-8215$.

(52) Heyd, J.; Scuseria, G. E. Assessment and Validation of a Screened Coulomb Hybrid Density Functional. J. Chem. Phys. 2004, $120,7274-7280$.

(53) Krukau, A. V.; Vydrov, O. A.; Izmaylov, A. F.; Scuseria, G. E. Influence of the Exchange Screening Parameter on the Performance of Screened Hybrid Functionals. J. Chem. Phys. 2006, 125, 224106.

(54) Blochl, P. E. Projector Augmented-Wave Method. Phys. Rev. B: Condens. Matter Mater. Phys. 1994, 50, 17953-17979.

(55) Kresse, G.; Joubert, D. From Ultrasoft Pseudopotentials to the Projector Augmented-Wave Method. Phys. Rev. B: Condens. Matter Mater. Phys. 1999, 59, 1758-1775.

(56) Monkhorst, H. J.; Pack, J. D. Special Points for Brillouin-Zone Integrations. Phys. Rev. B 1976, 13, 5188-5192.

(57) Ong, S. P. In Materials Project; Persson, K., Ed.; Lawrence Berkeley National Laboratory: Berkeley, CA, 2011.

(58) Becke, A. D. A New Mixing of Hartree-Fock and Local DensityFunctional Theories. J. Chem. Phys. 1993, 98, 1372-1377.

(59) Reiher, M.; Salomon, O.; Artur Hess, B. Reparameterization of Hybrid Functionals Based on Energy Differences of States of Different Multiplicity. Theor. Chem. Acc. 2001, 107, 48-55.

(60) Bader, R. F. Atoms in Molecules-A Quantum Theory; Clarendon

Press: Oxford, England, 1990; Vol. 22.

(61) Henkelman, G.; Arnaldsson, A.; Jonsson, H. A Fast and Robust Algorithm for Bader Decomposition of Charge Density. Comput. Mater. Sci. 2006, 36, 354-360.

(62) Tang, W.; Sanville, E.; Henkelman, G. A Grid-Based Bader Analysis Algorithm without Lattice Bias. J. Phys.: Condens. Matter 2009, 21, 084204 .
(63) Kepp, K. P. Consistent Descriptions of Metal-Ligand Bonds and Spin-Crossover in Inorganic Chemistry. Coord. Chem. Rev. 2013, 257, 196-209.

(64) Capdevila-Cortada, M.; Lodziana, Z.; Lopez, N. On the Performance of $\mathrm{DFT}+\mathrm{U}$ Approaches in the Study of Catalytic Materials. ACS Catal. 2016, 6, 8370-8379.

(65) Rosseinsky, D. R.; Lim, H.; Jiang, H. J.; Chai, J. W. Optical Charge-Transfer in Iron(III)Hexacyanoferrate(II): Electro-Intercalated Cations Induce Lattice-Energy-Dependent Ground-State Energies. Inorg. Chem. 2003, 42, 6015-6023.

(66) Alvarez-Moreno, M.; de Graaf, C.; Lopez, N.; Maseras, F.; Poblet, J. M.; Bo, C. Managing the Computational Chemistry Big Data Problem: The Iochem-Bd Platform. J. Chem. Inf. Model. 2015, 55, 95103. 